\title{
Krista Zach
}

\section{Rumänien}

Rumānien beherbergte während der $Z$ wischenkriegszeit unter den Ländern Südosteuropas die größte und auf dem Kontinent insgesamt die drittstärkste jüdische Gemeinde. ${ }^{1}$ Der vorwiegend in der neueren rumänischen Historiographie erweckte Eindruck, Rumāniens Juden seien - da dem Holocaust nicht überantwortet - auch meist davongekommen, alle Verfolgungen und alle Opfer des Terrors seien nur rumānischen Randgruppen wie z. B. den Legionären (der von Codreanu gegründeten antisemitisch-nationalistischen und christlich-mystischen "Eisernen Garde") oder der deutschen Truppenpräsenz im Lande zuzuschreiben, entspricht in dieser Form nur bekannte Quellen ignorierendem Wunschdenken, nicht aber der Realitāt. Verschiedene aus der Geschichte Rumäniens bekannte wirtschaftliche, politische wie strategische Gesichtspunkte, bukaresterseits auch ein gutes Maß an diplomatischem Kalkül bewirkten letztlich, daß kein Vertreter rumänischer Staatsmacht zwischen 1941 und

$1 \mathrm{Vgl}$. Raul Hilberg. The Destruction of the European Jews, New Yort 1985², 3 Bde, hier Bd. 2, S. 760 . In Rumänien hatte sich die Zahl der Juden nach 1918 durch die Gebietserweiterungen gegenüber Nitruminien etwa verdreifacht (vgl. Tabellen 1 und 3), ihr Bevölkerungsanteil machte 1930 aber nur rund 4,3\% aus. Dahingegen hatte Trianon-Ungam mit rund 473000 Juden (1941) im Vergleich zum Königreich Ungam bis 1918 nurmehr etwa halbsoviele Juden, s. Rolf Fischer, Entwicklungsstufen des Antisemitismus in Ungarn 1867 - 1939, München 1988, S. 136.

2 Die Tatsache einer deutschen Truppenprïsenz zwischen Oktober 1940 und August 1944, Stichwort „Heeresmission“, wurde seit den vierziger Jahren propagandistisch verwertet. Sowohl in der Presse wie auch in der Fachliteratur ist stets daher vorwiegend in rumänischen Arbeiten bis heute zu lesen, Rumānien sei ein vom Dritten Reich besetztes Land gewesen. Das Problem wurde bereits von Andreas Hillgruber (Hitler, König Carol und Marschall Antonescu. Die numänisch-deutschen Beziehungen 1938 bis 1944, Wiesbaden $1965^{2}$, S. $131 \mathrm{f}$.) dargestellt. Ein jüngerer Forscher aus laşi nahm diese Scheinproblematik kürzlich von neuem auf, um Rumäniens stantliche Souveränitāt in diesem Zeitabschnitt qualifiziert zu bestätigen. Vgl. Gheorghe Buzatu, Statutul intemational al României între 1939 şi 1945, in: Ders, Din istoria secretã a celui de al doilea räzboi mondial, Bucureşti 1988, S. 328-335: Trotz anderer Darstellungen in Presse und Teilen der Literatur sei Rumänien - anders als Abanien, Griechenland, Jugoslawien und ähnlich Ungam (bis Mär 1944), Bulgarien, Finnland - kein besetztes Land gewesen, sondern vielmehr ein Vertragspartner, „ein Satellit" (S. 332) und Antonescu "kein Quisling“. Da die Souverinität Rumäniens damals gar nicht in Frage gestanden habe, seien hierzu auch keine stantsvertraglichen Dokumente angefertigt worden (S. 328, 330). Auch Buzatu verweist $u$. a auf deutsche Parteistellen, die zur Besatzungsthese neigten (vgl. u. a eine Ausführung des SS-Gerichts vom 14.11.1943 über den Wehrdienst Volksdeutscher in der Waffen-SS, mit Hinweis auf völkerrechuliche Beweisnot und die dagegen gerichteten zahlreichen Schriftsätze aus dem $A$, das wiederum bestrebt war, Rumänien als „Verbündeten“ nicht zu irritieren: Reichsführer SS, Hauptamt SS-Gericht, Nr. 33, bes. S. 2 (in: PAMA Inland, Bd. II).

Die deutsche Heeresmission, die aus Ausbildungs- und später vermehrt auch aus Wachtruppen im Olfördergebiet bestand sowie an der Ostgrenze Rumäniens deutsche operative Verbande stelle, denen bis August 1944 rumänische zur Seite standen, die während des Osteldzuges weiter nach Bessarabien und in die Ukraine vorrückten, galten als „deutsche Truppen“ in Rumänien. Für die folgenden Ausführungen ist diese Klärung notwendig. 
1943 eine nennenswerte Zahl von Juden aus dem eigenen Staatsgebiet ${ }^{3}$ an die nationalsozialistischen Vernichtungslager lieferte. Und auch wenn es von deutscher Seite Planungen dafür gegeben hat, konnte aus Rumänien kein direkter Zug in die Gaskammern abgefertigt werden.4 Dennoch gab Rumānien wāhrend des Zweiten Weltkriegs jüdische Staatsbürger der Vernichtung preis. Unter dem zynischen Vorwand,

3 Die Sachlage bedart hier einer Einschränkung wie einer Erläuterung. Die Einschränkung bezieht sich auf im Reichsgebiet 1942 lebende numanische Juden unbestimmter aber geringer Zahl, die Außenminister Davidescu 1942 deutschem Vertahrenswillen überließ (S. IfZ, MA 1538/4). Diese Zusage wird Anfang 1943 l. einer Vortragsnotiz des VLR Wagner für Ribbentrop vom 20.4.1943 wieder zurückgenommen; Rumānien wünscht nunmehr die Rückkehr aller seiner aul Reichsgebiet befindlichen Juden. Dafür ist es jedoch, trotz erteilter deutscher Zustimmung - das RSHA stoppt alle diesbezüglichen Deportationen nach dem Osten -, zu spit (ADAP, Serie E, Bd 5, Nr. 363, S. 661 f.)

Die Enāuterungen betreffen erstens die von der deutschen Einsatzgruppe $\mathrm{D}$, Einsatzkommando $10 \mathrm{~b}$ der $\mathrm{Si}$ cherheitspolizei, auf rückerobertem Territorium in der Bukowina und in Bessarabien vorgenommene Exekutionen im Juli 1941. Obgleich sie in beiden Gebieten keine Besatrungshoheit ausübten (vgl. dazu die Studie von Hermann Weber, Die Bulkwina in Zweiten Weltkrieg. Völkertechtliche Aspekte der Lage der Bukowina im Spannungsfeld zwischen Rumänien, der Sowjetunion und Deutschland, Frankfurt 2M. 1972, S. 43. 45) operierten sie gemeinsam mit rumänischer Gendarmerie und Amee (ebenda, gemäß der Zusammenstellung von Tätigkeits- und Lageberichten sowic Ereignismeldungen von Juni bis August 1941 nach IMT. und NG-Quellen, vgl. Hugo Gold, Geschichte der Juden in der Bukowina Ein Sammelwerk. 2 Bde., Tel Aviv 1958 und 1962, hier: Bd. 2, S. 70ff.) während einer viertigigen ex-lex-Periode vom 6-10.7.1941 im völkerrechtlich leeren Raum. Die Bukowina wurde ebenso wie Bessarabien am 10.7.41 wieder unter rumanische Stantshoheit gestellt (Nbg. Dok. NO-4135; vgl. auch Martin Broszat, Das Dritte Reich und die rumānische Judenpolitik, in: Gutachten des IfZ, München 1958, S. 102-183, hier: 143-152; Weber, Bukowina, S. 33-36). Zweitens beziehen sich die Erlāuterungen auf die Exekutionen rumänischer Juden in den Lagem und Ghettos Transnistriens sowie auf die Uberstellung von Arbeitskrätten aus dieser Gruppe an deutsche Lager östlich des Bug.

4 Die Forschungslage hinsichtlich einer von deutscher Seite geplanten Deportation der rumānischen Juden ist noch sehr unzureichend. Den Quellen ist hierzu ein Aleingang des RSHA und seines übereifrigen Judenberaters in Bukarest seit Ende 1940, SS-HStF Gustav Richter, zu entnehmen, die bereits einen Zeitpunkt, ein vorlāufiges Lager und einen jüdischen Personenkreis zum Abtransport nach Polen anzugeben wußten Der SD teilte am 26. Juli 1942 Unterstaatssekretär Luther im Auswärtigen Amt mit: „Es ist vorgesehen, etwa ab 10.9.1942 nunmehr auch Juden aus Rumānien in Sonderzūgen nach dem Osten abzubefórdem." Gemeint war, die Juden aus Binnennumänien in laufenden Transporten nach dem Distrikt Lublin zu verbringen, wo der arbeitsfähige Teil arbeitseinsatzmäßjg eingesetzt wird, der Rest der Sonderbehandlung unterzogen werden soll“. (Eichmannprozeß, Dok. 181 und 562.) Angesichts der letzten Deportierungen nach Transnistrien von insgesamt 5397 Juden aus Bukarest und der Bukowina im Herbst 1942 tauchten deutscherseits nochmals āhnliche Meldungen auf (IfZ, MA 1538/2). Ubersehen wurde dort zunāchst, daß die rumänische Regienung keinem dieser Vernichtungskonzepte zugestimmt hatte, vgl. u. a dazu Dementi des Deutschen Gesandten in Bukarest, v. Killinger: ,... Von einem Abschluß der Verhandlungen (mit Bukarest, d. Verf.) ist gar keine Rede..." (Eichmannprozeß, Dok. 178). Nach vielfältigen Verzögerungsmanōvem lehnte es die rumänische Seite schließlich ab, sich in das Judenvernichtungskonzept der Nationalsozialisten einbeziehen zu lassen, vgl. IfZ, MA 1538/3 (20.1.43 und 17.11.43). Die Aufzeichnung eines Gesprächs zwischen v. Ribbentrop und Ministerpräsident Mihai Antonescu vom 5.8.1944 erklärt diese rumänische Entscheidung mit diplomatischen Erwägungen - Hinweise auf Kritik auswärtiger Botschafter und auf den angeblich antirumānischen Akzent der Judendeportation aus Nordwestsiebenbürgen durch die ungarischen Behörden, vgl. ADAP, Serie E, Bd. 8, Nr. 149, S. $278 \mathrm{ff}$

Wie aus einem Brief Himmlers an den Chel der Gestapo, Heinrich Müller, hervorgeht, hatte man in Berlin bereits Anfang 1943 bezüglich der Beteiligung Rumāniens an der "Endlösung" resigniert. Himmler schreibt: „Betr.: Gefāhrdung der im Rahmen der europäischen Gesamtlösung geplanten Judenlōsungsfragen in Rumānien... Ihren Bericht vom 1.1.1943 ... habe ich gelesen. In Rumänien ist im Augenblick meines Erachtens gar nichts zu machen. Ich selbst neige zu der Ansicht, daß es besser wäre, wenn wir unseren Juden-Bearbeiter von dort zurückzögen... In den nächsten Monaten wird auf dem Judengebiet dort bestimmt nichts geschehen. Wenn wir einen Bearbeiter dort haben, kann es nur sein, daß wir mit irgendwas beschuldigt werden..." (IIZ, MA 1538/3; gleichfalls in: Karl M. Reinerth, Die Deutschen in Rumänien von 1941 bis 1945. Teil III (Quellen) Typoskript o. O, o. J, S. 230). 
sie schützen zu müssen, wurden wirtschaftlich und staatsbürgerlich entrechtete Juden zwangsweise umgesiedelt. In den vom Krieg teils schon zerstörten Steppenlandschaften der Ukraine zwischen Dnjestr und Bug, in den Ghettos und Lagem Transnistriens oder auf dem Transport dorthin starben viele aus Rumānien deportierte Juden. So wie deren Staatsbürgerschaft nach Überschreiten der Dnjestrgrenze, blieb der staatsrechtliche Status "Transnistriens" (in der Sowjetukraine) - erst damals so benannt - wohl absichtlich im Unklaren. Das Gebiet war im Juli 1941 von deutschen und rumänischen Truppen eingenommen worden und unterstand zwischen August 1941 und 1943/44 rumānischer Zivilverwaltung, da General Ion Antonescu, der rumānische Staatschef, die förmliche Annexion durch Bukarest nicht wünschte; Einzelheiten der Verwaltungszustāndigkeit wurden zwischen Deutschen und Rumānen im Vertrag von Tighina (30. August 1941) geregelt; die Quellen belegen eine eher rudimentäre rumānische Verwaltung durch Polizeiorgane.s

Die Lage der Juden in Transnistrien, überwiegend aus den östlichen Teilen Rumāniens, zum geringen Teil auch aus Binnenrumānien deportiert, und der Juden anderer Nationalität, die teils in Ghettos, teils in Arbeits- und Konzentrationslagem leben mußten, war 1941/42 nicht weniger fatal, als die der KZ-Häftlinge im deutschen Herrschaftsgebiet. Entbehrungen, Krankheit, Seuchen, Mißhandlungen, Zwangsarbeit und willkürliche Exekutionen bildeten bis 1943 in Transnistrien den jüdischen Alltag. Kleinere und heftigere Terrorwellen, Arbeitsdienste, Lagerinternierung und hāufig die bürgerliche, wirtschaftliche und politische Entrechtung prägten dagegen das jüdische Dasein im Binnenland. Neben den rumänischen und den deutschen Schergen waren auch Ukrainer und Sowjets für die Geschicke der Juden verantwortlich, entsprechend der politischen Situation in den Provinzen Transnistrien, Bessarabien und Bukowina, die zwischen 1940 und 1944 viermal die Verwaltung und die Staatszugehörigkeit wechselten.

Auch unter Rumāniens Juden gab es eine hohe Zahl von Opfern der Willkür. Neben den Folgen von Krieg und Deportation gingen sie ebenso auf nationalsozialistische Befehle wie auf antisemitische rumänische Ausschreitungen nationalistischer Gesinnungsgruppen zurück; auch sowjetische Mittāterschaft ist auszumachen. Aus den vorhandenen Quellen ist die Frage nach den tatsächlichen Verursachern der einzelnen Aktionen nicht immer genau zu klären. Der Genozid hat, gleichsam in einem exterritorialen Abseits, auch unter Rumäniens Juden stattgefunden, wennzwar vielfach in an-

5 Am 19.8.1941 übemahm Rumānien vom deutschen OKW das Gebiet Transnistrien in seine Zivilverwaltung - mit einem Gouverneur, Polizei-, Gendarmerie- und Verwaltungskräften, ohne es jedoch zum numänischen Hoheitsgebiet zu erklären. Hierin besteht der gravierende Unterschied zur stantsrechtlichen Lage gegenüber Bessambien und der Bukowina. Deutscherseits bestand Hoffnung, Rumänien durch mögliche Gebietserwerbung von „Transnistrien“ stärker an sich zu binden, vgl. Weber, Bukowina, S. 34 ff, Antonescu blieb jedoch zunïckhaltend. Im Gebiet der südlichen Ukraine teilten sich die deutschen und rumänischen Stäbe die Verwaltungs-, Wirtschafts- und Sicherheitsaufgaben; die Trennlinie zwischen beiden Bereichen bildete der Bug. Die Rumānen waren östlich des Bug bis zum Dnjestr zuständig, die Deutschen östlich des Flusses, was für die nach Transnistrien deportierten rumänischen Juden wichtig war. Das zwischen Brig.General Tätireanu und GenMajor Hauffe am 30.8.1941 geschlossene Abkommen von Tighina sagte nichts aus über die Hoheitsrechte in der Südukraine (vgl. IfZ, MA 1538/4). 
derer Form ${ }^{6}$ als in Auschwitz und anderen Vemichtungsstātten. In seinen Erinnerungen nennt der rumānische Oberrabbiner Alexandru Şafran ihn treffend den „vergessenen Holocaust ${ }^{\prime \prime}$.

Dieser ${ }_{n}$ vergessene Holocaust " betrifft insbesondere Vorfälle wāhrend des deutschrumānischen Aufmarsches gegen die Sowjetunion an und hinter der Pruthlinie. Erst am 3. Juli 1941, fast zwei Wochen nach dem Angriff auf die Sowjetunion, geriet hier die Ostfront in Bewegung. Die Aktionen gegen die Juden begannen mit dem Pogrom in Jassy/laşi vom 29. Juni und kulminierten schließlich im Oktober weit ōstlich dieser Linie in den Judenmassakern von Odessa. ${ }^{7}$ In wenigen Wochen starben unzählige rumänische und ukrainische Juden, deren Leiden dokumentarisch kaum nachweisbar ist.

In der Zwischenkriegszeit lebten in allen Teilen Rumäniens Juden. Sie unterschieden sich in ihren kulturellen Eigenheiten wie Muttersprache/Verkehrssprache, Assimilationsgrad an die regionale Mehrheitsbevölkerung und Formen mosaischer Tradition (Orthodoxe, Neologen, Chassidim u. a.). In allen Regionen gab es sowohl sephardische wie (in der großen Uberzahl) aschkenasische Juden. Das sprachliche Verhalten war und blieb vielgestaltig und wandelbar, die Gebildeten waren mehrsprachig.

6 Auf diese quasi-Exterritorialität wurde schon in Anm. 3 (Einsatzgruppe D, Einsatzkommando 10 b/Ohlendorf) verwiesen. Das Einsatzkommando 10 b hatte Czemowitz am 6.7 .1941 abends erreicht und an 10.7.1941 wieder veriussen; sein Operationsraum reichte von hier bis Odessı In Czernowitz wurden Juden aufgrund von vorhandenen Listen und im Zusammenwirken mit ruminischen Armee- und Verwaltungsorganen verhaftet und liquidiert (vgl. Gold, Geschichte Bukowina, Bd. 2, S. 17). Entsprechend ist den erhaltenen Ereignismeldungen zu entnehmen: ,... Am folgenden Tage (8.7.42) wurden ce 100 jüdische Kommunisten vom Kommando erschossen. Zusammen mit den Judenhinrichtungen durch die rumänische Wehrmacht und Polizei sind insgesamt mehr als 500 Juden im Leufe des 8. und 9. d. M. erschossen worden." (vgl. Nbg. Dok NOKW 587, vom 9. Juli 1941). Auch die Ereignismeldungen aus der Ukrine vom 1.8. und 29.8.1941 verweisen darauf: „In Czemowitz wurden von etwa 1200 festgenommenen Juden 682 im Zusammenwirken mit der rumänischen Polizei erschossen." (Nbg. Dok. NO-2950) Es folgte eine Zwischenbilanz: In Czernowitz und bei Durchkimmen ostwirts Dnjestr weitere 3106 Juden und 34 Kommunisten liquidient. (Nbg. Dok. NO-2837). Der rumānischen Seite wird vorgeworfen, daß „die rumānische Polizei ... nur stellenweise scharf gegen Juden“ vorgehe. "Die Zahl der von ihr durchgeführten Liquidationen ist nicht festzustellen." (Nbg. Dok. NO-2950). Sie habe es nicht fertiggebracht, einen Pogrom anzustiften und die Feindschaft der Rumanen in der Provinz gegen die Ukrainer ausschließlich auf die Juden umzulenken (Nbg. Dok. NO-4135).

In den wenigen Tagen des deutsch-rumānischen Vormarsches an der Pruthlinie, etwa vom 3.7.1941 bis zur Festigung der ruminischen Zivilverwaltung in der Bukowina und in Bessarabien nach dem 10.7.1941, ist eine unbekannte Zahl von Juden dieser Provinz ermordet worden. Eindeutige Aussagen über die Zahl können auch die bekannten Quellen nicht vermitteln, vgl. auch Hilberg, Destruction, Bd. 2, Tab. 8-20, S. 771; Bd. 3, Tab. B-1, S. 1219. Schätzungsweise kamen in der Folgezeit nicht mehr so viele deportierte Juden aus diesen beiden Gebieten ums Leben. Vgl. den Versuch einer Aufstellung über die Zahl der Opfer von Sabin Minuili und Wilhelm Filderman, Regional Development of the Jewish Population in Romania, Roma 1957. S. 8 .

Die rumānische Literatur beruft sich ebenfalls mit statsrechtlicher Scheinargumentation auf die Grenzziehungen vom August 1940: Ausgenommen ganz vereinzelte und flüchtige Initiativen örticher Verwaltungsorgane wurden Rumäniens Juden nicht in Ghettos gestopft, mußten im allgemeinen nicht den anrūchigen gelben Stern' tragen, ... haben die Schrecken der Vemichtungslager nicht kennengelemt, und das weder auf dem Landesterritorium, noch durch Deportation auf fremdes Gebiet." Vgi. Aurel Karepki/Maria Covaci, Zile însîngente la leşi (28 - 30 junie 1941), Bucureşti 1978, S. 20, Ubersetzung d. Verf. Diese Darstellung wird dem komplexen Sechverhalt nicht gerecht.

$7 \mathrm{Vgl}$. den Beitrag über die Sowjetunion in diesem Band. Die rumänische Forschung übergeht dieses Judenmassaker, obgleich 24000 Opfer geschätzt wurden (vgl. Gold, Geschichte Bukowina, Bd. 2, S. 22); Hilberg (Destruction, Bd. 1, S. 306 f.) nennt für Odessa und Umgebung mit Bezug auf deutsche und rumänische Schätzungen 25 - 30000 Opfer (Anm. 74). 
Es scheint, als hätte sich die Mehrheit der Juden Rumäniens nach 1918 gegen einen jüdischen ${ }_{n}$ Minoritāten-Status “ ausgesprochen, und somit auch gegen dementsprechende politische Aktivitāten. Eindeutig belegen läßt sich diese Annahme nicht, da sich sowohl die Abgeordneten der jüdischen Verbānde im Bukarester Parlament zwischen 1923 und 1933 auf den Minderheitenschutz beriefen wie auch einzelne Juden in zahlreichen Petitionen, die in den dreißiger Jahren dem Völkerbund vorgelegt wurden. ${ }^{8}$ Es steht allenfalls fest, daß sich die Juden Rumäniens der jüdischen Kultusgemeinde zugehōrig fühlten. Ihrer Herkunft aus verschiedenen Staats- und Kulturtraditionen gemäß blieben die regionalen Unterschiede bis zur Auflösung der jüdischen Gruppen während der Kriegs- und frühen Nachkriegszeit weitgehend bestehen und unter vielerlei Aspekten auch politisch bestimmend. „Die Juden“ Rumāniens gab es nur in konfessionellem und statistischem Zusammenhang.

Alle regionalen Gruppen hatten ihre eigenen politischen Verbände; deren Dachorganisation, der Verband der Juden Rumäniens (Uniunea Evreilor din România, aktiv von 1919, bzw. 1923 bis 1941), war lose gefügt und diente hauptsāchlich der Vertretung nach außen - also gegenüber Bukarest wie der Kontaktaufnahme mit auslāndischen Gesandtschaften, dem Völkerbund in Genf und den internationalen jüdischen Organisationen. Die innerjüdische Kommunikation erscheint dagegen, wohl infolge unterschiedlicher Herkunft und Tradition, schwerfällig. 9 Dem geringen Grad von Kommunikation der jüdischen Regionalgruppen untereinander entsprach das unterschiedliche Verhalten der Bukarester Politik, gestuft nach Regionen. Besonders deutlich kam das 1940 und 1941 angesichts der antisemitischen Maßnahmen zum Ausdruck, doch hatte es im Osten und Nordwesten Rumāniens auch während der dreißiger Jahre schon Beispiele dafür gegeben.

Die Entscheidungen Bukarests bezüglich der Juden waren durch historisch bedingte, ideologische und wirtschaftliche Überlegungen zwar beeinflußt, insgesamt aber doch ein Amalgam aus unklaren oder gar nicht definierten Vorurteilen und handfesten wirtschaftlichen und außenpolitischen Erwartungen. Diese Verkettung muß in die Betrachtung der Politik Rumäniens gegenüber den Juden einbezogen werden, will man monokausale Erklärungen vermeiden. Es erscheint wenig sinnvoll, darüber zu mutmaßen, ob König Carol II. im August 1940 die ersten Gesetze, die die Juden persōnlich entrechteten und wirtschaftlich entscheidend $z \mathbf{u}$ schwächen versprachen, tatsāchlich nur erlassen hatte, um den Territorialforderungen Ungarns, die Berlin unterstützte, zuvorzukommen und den Zweiten Wiener Schiedsspruch (30. August 1940) abzuwenden, oder ob sie allein aus der zunehmenden wirtschaftlichen Abhāngigkeit

B Dies ist ein bezeichnendes Beispiel für die Schwierigkeiten, denen sich der Historiker bei vielen Fragen zur jüdischen Geschichte in Rumànien seit 1918 gegenübersieht. Weitgehend fehlt hier noch Primärforschung. Wortühret der Ablehnung einer jüdischerseits betriebenen Mindertheitenpolitik gegenüber Bukarest war Dr. Mayer-Ebner in Czernowitz, der während der Zwischenkriegszeit die Zionisten gegenüber den eher assimilationsbereiten Juden in Buterest um Dr. W. Filderman vertrat, vgl. Gold, Geschichte Bukowina, Bd. 2, S. 3; Encyclopaedia Judaica, Jenusalem 1971/1972, hier: Bd. 14, Sp. 396. In Siebenbürgen befürworteten die jüdischen Politiker eher Fildermans Linie einer gesamtjüdischen Minderheitenhaltung, vgl. ebenda, Bd. 15, Sp. 1344.

9 Eine Gesumtdarstellung der Geschichte der Juden, deren Wohngebiete 1918 zu Ruminien kamen, fehit. Vgl. daher ebenda, Bd. 14, Sp. 390-394, 396-398. 
Rumāniens wie anderer Staaten Südosteuropas von Deutschland ${ }^{10}$ zu begründen sind. Für König Carol II. gab es neben dem außenpolitischen Balanceakt sehr gewichtige innenpolitische Gründe, so daß die Anfang August 1940 in großer Aufmachung im Amtsblatt Monitorul Oficial erlassenen Judengesetze u. a. auch eine Art ultima ratio zur Bewahrung seines Thrones darsteliten: Angesichts rumānischer Flüchtlingsströme aus Bessarabien und der Bukowina ins Binnenland und der lärmenden Forderung der Legionäre nach antijüdischen Aktionen mögen diese Augustgesetze eine Maßnahme zur Beruhigung der alarmierten, für nationalistische Parolen sehr empfänglichen Öffentlichkeit gewesen sein. ${ }^{11}$ Es darf auch nicht übersehen werden, daß König Carol II. sich auf ein bereits vorhandenes Paradigma antijüdischer Gesetzesvorhaben aus der kurzen Regierungszeit des abgelösten Kabinetts Goga stützen konnte. Obgleich der damals aufgestellte Maßnahmenkatalog, der sich gegen Juden im Staatsdienst, in staatlichen Monopolbereichen (Tabak, Alkohol), in Theater, Film, Presse, gegen jüdische Anwälte, Ingenieure, Ärzte, Geschichtslehrer etc. richtete, eigentlich über das Planungsstadium noch nicht hinausgetreten war, hatte er in den Ostprovinzen bereits Anwendung gefunden. Allein in Czernowitz wurden 14 jüdische Zeitschriften und in Bessarabien alle jiddischen Blätter verboten. ${ }^{12}$

10 Die Frage nach dem Ausmaß der Abhängigkeit Rumäniens vom Deutschen Reich ist in der westlichen Nachkriegsliteratur meist nur pauschal und undifferenziert erörtert worden. Außenpolitische Rahmenbedingungen angesichts der deutschen Dominanz in Südosteuropa seit 1939 standen im Vorfeld der Uberlegungen. Diesen Fragen ist neben Andreas Hillgnuber am gründlichsten bislang in mehreren Arbeiten Martin Broszat nachgegangen. Abgesehen von dem bereits zitierten Gutachten sind das: Faschismus und Kollaboration in Ostmitteleurops zwischen den Weltkriegen, in: Vierteljahrshefte für Zeitgeschichte (VIZ) 3 (1966), S. 225-251 und Deutschland - Ungam - Rumänien. Entwicklung und Grundfaktoren nationalsozialistischer Hegemonial- und Bündnispolitik 1938 - 1941, in: Historische Zeitschrift (HZ) 206 (1968), S. 45-96. Mit Bezug auf Werner Conzes grundlegende Studie, Strukturkrise des östlichen Mitteleuropa vor und nach 1919, in: VfZ 4 (1953), S. 518-538, formuliert Broszat die These von den "verspäteten Nationen" Ostmitteleuropas, bei denen sich in der Zwischenkriegszeit eine bestimmte Korrelation zwischen einer "Tendenz zu faschistischem Radikalismus und Irrationalismus" gepart mit einer "Kollaborationstendenz" entwickelt habe (vgl. Faschismus, S. 227). Viel weniger theorieverhaftet, datenreich und faktennah erscheint Broszats Uberblick von 1968, in dem die Beziehungen Ungarns und Rumāniens von 1938 bis zum Beginn des Krieges im Osten untersucht werden; der "Satelliten ${ }^{4}$-Status dieser beiden Länder wird denen mit sehr eingeschränkter Souveränität wie die Slowakei oder Kroatien gegenübergestellt. Forschungslücken werden in ders, Deutschland (S. 46, 82-96) aufgezeigt.

11 Der rumänische Text der beiden Gesetze in: V. Pantelimonescu, Statutul evreilor din România 1918 1941, Bucureşti 1941, S. 37-76. Die Stimmungslage in Bukarest hatte der britische Gesandte Hoare bereits am 14.4.1938 dem Foreign Office angezeigt, antijüdische Maßnahmen sollten dazu dienen, die rechtsextremen Gegner Carols II. bei der Eisernen Garde „zu zähmen“" (s. PRO, FO 371/22349 - 106834, R 4061, $f$. 162; Hillgruber, Rumänisch-deutsche Beziehungen, S. 238; Armin Heinen, Die Legion 'Erzengel Michael' in Rumänien. Soriale Bewegung und politische Organisation. Ein Beitra zum internationalen Faschismus, München 1986, S. $169 \mathrm{ff}_{2}$ 183-187.

Nach den enormen Gebietsverusten im Sommer 1940 wurden die antisemitischen Gesetze auch propagandistisch wirksam zur Ablenkung einer irritierten Offentlichkeit eingesetzt. Hillgruber untersuchte die Hintergründe der Augustgesetze zwar in etwas verkürzter Perspektive (aus außenpolitischen Gründen getrof(en"), erkannte aber richtig ihren propagandistischen Aspekt (sie hätten „praktisch nicht viel Bedeutung“ gehabt), vgi. S. 236. Otwohl die Ähnlichkeit mit den Nümberger Gesetzen frappierend sei, habe Berlin, laut einer Mitteilung des ehemaligen deutschen Gesandten in Bukarest, Fabricius, diese Gesetze nicht veranlaßt (ebenda, S. 238). Es müßte noch untersucht werden, ob die Kontakte des späteren Generaldirektors für Judentragen, Radu Lecca, zum Amt Rosenberg hier einen Weg weisen, vgl. auch Broszat, Gutachten, S. 107.

12 League of Nations Archive (im folgenden: LNA) R 3943, 4/32402/13396: 30.4.1938, S. $5 \mathrm{ff}$. Am 14.4.1938 berichtete der britische Gesandte Hoare dem Foreign Office, Außenminister Petrescu-Comnène habe geāuBert, man befürchte Terrorakte der Legionäre, falls die Regierung nicht antijüdische Maßnahmen anordnete (PRO, FO 371, 22349 - 106834, R 4061, f. 162). Am 10.8.1938 berichtet Farquar dem Foreign Office, Carol habe die politische Hypothek der antisemitischen Gesetzentwürfe der Regierung Goga zu tragen, obgleich sie mit seiner Politik der wirtschaftlichen Festigung insofern kollidiere, weil er dafür die Unterstützung der Juden benötige (ebenda, 22350 - 106834, R 7054, f. 156, 157). 
Der Versuch, monokausale Begründungen zu vermeiden, sollte auch auf einen zweiten, mit der Entrechtung der Juden zusammenhängenden Komplex angewandt werden, und zwar auf die Frage, ob der Vorwurf der Bolschewisierung und Spionage, der öffentlich gegen die Juden der beiden Landesteile Bessarabien und Bukowina in der Zwischenkriegszeit - vor, während und nach der sowjetischen Besetzung dieser Provinzen 1940/41 - erhoben wurde, mehr war, als nur propagandistischer Vorwand, um der rumänischen wie der internationalen Offentlichkeit die harten, in Rumānien sonst unüblichen Maßnahmen des Staates gegen die Juden in den beiden östlichen Provinzen Bessarabien und Bukowina in den Jahren 1941 bis 1944 zu begründen. Denn die von den Sowjets vorgenommenen allgemeinen Enteignungsmaßnahmen wurden nur im Falle der Juden ab Juli 1941 nicht zurückgenommen, die Juden wurden weiter entrechtet und schließlich deportiert. Die spezifischen Zusammenhänge zwischen Enteignung, Entrechtung und Deportation nach Transnistrien sowie die Frage nach der Befürwortung der Auswanderung dieser jüdischen Gruppe durch rumānische Politiker bis hin zum ersten kommunistischen Premier, Petru Groza, müssen noch genauer erforscht werden. ${ }^{13}$

Der latente Antisemitismus war 1940 in Form von tātlichen Angriffen gegen die Juden zum Ausbruch gekommen. Schon seit 1919 jedoch machten fast alle politischen Gruppen damit Politik. Weder König Carol II. noch Petru Groza waren tatsāchlich Antisemiten. Aber sie bedienten sich einer vorhandenen politisch-ideologischen Konjunktur, des Antisemitismus, wie das andere Regierungen schon in Altrumānien getan hatten.

Nach 1918 zeigten sich regionale Unterschiede in der Behandlung der Juden Rumāniens durch die Bukarester Politiker zunāchst im Atmosphārischen. Sie entsprachen dem altrumänischen Komplex, die Juden - vor allem die aus den neuen Gebieten - seien assimilationsunwillige ${ }_{n}$ Fremde", Menschen, die nicht ${ }_{n}$ Rumānen ${ }^{*}$ werden wollten. Diese Meinung hatte sich im 19. Jahrhundert angesichts Jiddisch sprechender, in ihrer Stetl-Kultur verharrender Ostjuden gebildet, die in kompakten Gruppen in der Moldau lebten; sie wurde nach 1918 auf die teilweise āhnlich strukturierten Gemeinden in Bessarabien und der Bukowina übertragen. Deutschsprachige Juden in Czernowitz und ungarischsprachige im Banat und in Siebenbürgen verstärkten diese diffuse Meinung. Der erwünschte Wandel zu rumänischsprachigen Juden war nur in den größeren Stādten Altrumāniens erfolgt. Und nur diese Juden konnten offensichtlich von Bukarester Politikern als Vollbürger akzeptiert werden. Von ihren Glaubensbrüdem aber wurden sie abschātzig als ,Regatler' [,regat" (rum.) = Königreich Altrumänien] bezeichnet.

Ein zweiter gewichtiger Faktor für die Behandlung der Juden durch die Bukarester Politik war ihre wirtschaftliche Leistungskraft. Auch wenn die statistischen Angaben eher zu interpretatorischer Zurückhaltung mahnen und eine nach Minderheitengrup-

13 Das war schon nach Eriaß der Judengesetze vom August 1938 so, wie G. G. Fitzmaurice dem Foreign Office am 30.9.1938 schrieb, vgl. PRO, FO 22351 - 106834, R 8181, f. 197, 198. Die antijüdischen Maßnahmen kamen erst nach dem Sturz Carols II, ab September 1940, verstäkt zur Anwendung. Vgl. Gold, Geschichte Bukowina, Bd. 2, S. $12 \mathrm{ff}$. und $16 \mathrm{ff}$. In einem Brief deutet Filderman gegenüber Stantschef Antonescu am 25.10.1941 an, daß in der Bukowina und in Bessambien gegenüber anderen Landesteilen wie Altrumānien, Siebenbürgen und Banat mit rweierlei Maß gemessen, die Juden der zweitgenannten Provinzen „privilegiert" seien, NA 871.4016/254. Zu Groza vg1. NA RG 226, 121331 vom 2.4.1945. 
pen getrennt aufgeschlüsselte Wirtschaftsstatistik in Rumānien nicht veröffentlicht wurde, beweisen viele Einzelaussagen die Bedeutung der Juden als Wirtschaftsfaktor; in den Verhandlungen des Verbandes der Juden Rumäniens über die Verschonung vor Deportation und Entrechtung spielt dieser Aspekt, wie Briefe des Prāsidenten der Vereinigung Rumānischer Juden und Vorsitzenden der jüdischen Gemeinde Bukarests, Wilhelm Filderman an Regierungschef Antonescu andeuten, eine wesentliche Rolle. Die von den Juden Binnenrumäniens ab dem zweiten Halbjahr 1942 geleisteten Sonderabgaben und Steuern subventionierten den Krieg im Osten nicht unwesentlich. ${ }^{14}$ Auch wurden staatlicherseits Möglichkeiten eingeräumt, sich durch die Zahlung einer entsprechenden Summe von Arbeitsdienst und von der Deportation freizukaufen oder eine Ausreisegenehmigung aus Rumānien zu erhalten. In Bessarabien und der Bukowina dagegen konnte der rumänische Staat bereits von den Sowjets enteignetes jüdisches Vermögen sofort übernehmen und die ehemaligen jüdischen Besitzer abschieben.

Die Literatur beschränkt sich im Falle Rumāniens im wesentlichen auf Erlebnisund Erinnerungsberichte sowie auf knappe Ubersichtsartikel; eine wissenschaftliche Bearbeitung, die Erschließung der zahlreich vorhandenen (westlichen) Archivquellen, hat noch nicht stattgefunden. Es fehlen sowohl Untersuchungen zur Geschichte der Juden in einzelnen Provinzen Großrumāniens wie eine monographische Gesamtstudie zur Judenproblematik während der $Z$ wischenkriegszeit und vor allem im Zeitraum 1941/1945; damit steht Rumānien allerdings nicht allein. ${ }^{15}$

Die intemationale Holocaustforschung konnte im Fall Rumānien fast ausschließlich auf juristische Gutachten zurückgreifen; quellengestützte Untersuchungen fehlten weitgehend. Sie beruhte also z.B. auf der Prämisse, Rumänien habe im fraglichen Zeitraum vollstāndig in der Abhāngigkeit Deutschlands gestanden. Von Nischen für souverāne Entscheidungen Bukarests in außen- wie innenpolitischen Belangen zu sprechen war daher nicht opportun, denn Rumänien habe gar keine eigene Judenpolitik betreiben können. Gerade in dieser Frage ist historische Problematisierung erfor-

14 Die Juden Bessarabiens und der Bukowina würden im Sinne einer Sippenhaftung mit Deportation bestraft, da kommunistische Agenten (andeutungsweise - sowjetische Juden) dort angeblich provoziert hätten. Dagegen protestiert Filderman, bezeichnet die Maßnahmen als wirtschaftlich unvernünftig und weist auf die von den Juden der übrigen Provinzen entrichteten Sondersteuern und Sonderabgaben hin, vgl. Hillgruber, Rumänisch-deutsche Beziehungen, S. 239, det diese Sonderleistungen als Sühnemaßnahmen“ bezeichnet. In den Berichten der Deutschen Gesandtschaft wird von „Ausnahms- und Wiedervereinigungssteuem" gesprochen, die ein Dekret vom Mai 1942 den Juden auferlegte (IfZ, MA 1538/4). Zu den Sonderabgaben vgl. ebenda

15 Für den Zeitraum bis 1918 liegt nur eine zwar weitgefächerte, aber polemisierende oder apologetische Literatur der „chestiunea evreiasci" (num. Judenfrage") im 19. und frühen 20. Jahrhundert vor. Dies wird auch in einem gekürzt veröffentlichten Aufsatz neueren Datums über jüdische Kulturzeugnisse beklagt: Paul Pe trescu, Istorie şi simbolistica în arta populara a evreilor din România (S. 117-138), den der Verfasser freund. licherweise in voller Lange zur Verfügung stellte, vgl. bes. S. 117 f., 122.

Ähnlich außert sich auch Lloyd A. Cohen, The Seeds of Romanian Anti-Semitism, der etwas ausführlicher auf das kontroverse Schrifttum zur Judenfrage in Rumänien besonders anhand von I. B. Brociner, Chestiunea Izraeliţilor români, Bucureşti 1910, eingeht (Typoskript 1985, Boston College EERC, 31 S., bes. 12-17). In den bekannten Arbeiten über die Juden im Habsburgerreich sind die Informationen für die Regionen Siebenbürgen, Banat, Kreisch-Marmarosch bzw. Bukowina zu unspezifisch bzw. nicht nach KJeintegionen geordnet.

Ein Sammelband macht auf den insgesamt unbefriedigenden Bearbeitungszustand für das Judentum Galiziens, der Bukowina und angrenzender Gebiete in der Fachliteratur aufmerksam: Gotthold Rhode (Hrsg.), Juden in Ostmitteleuropa von der Emanzipation bis zum Ersten Weltkrieg, Marburg 1989, vgl. S. VIII f. 
derlich. Hierzu ein typisches Beispiel: Während die teils unerbittlich klingenden Judengesetze Rumāniens in den vierziger Jahren in älterer westlicher Literatur meist schon als Gesetzesrealitāt betrachtet wurden, sind neuere Werke (z. B. Hilberg ${ }^{2}$ ) in ihrer Interpretation viel ausgewogener. Seit einigen Jahren beschäftigt sich auch die rumānische Fachliteratur vorsichtig mit dieser bislang verschwiegenen Thematik.

Sehr viel günstiger ist heute die Quellenlage für die Erforschung der Judenproblematik Rumāniens in der Zwischenkriegszeit und bis nach dem Zweiten Weltkrieg. Die westlichen Archive sind im wesentlichen frei zugänglich, was vor allem für die Zwischenkriegszeit Einblick in die internationale Dimension des Problems gestattet: Die westlichen Māchte, der Völkerbund und die internationalen jüdischen Organisationen waren sehr gut informiert und z. T. der Fülle von Klagen und Berichten aus Rumānien überdrüssig.

Der Zugang zu den Archiven in Rumänien ist beschränkt; nur in seltenen Fällen wurde Forschern aus westlichen Lāndern bislang Einblick gewāhrt. Allein über rumānische Publikationen die Auszüge aus den Quellen zu zitieren, bietet eine indirekte, aber nicht nachprüfbare Möglichkeit, diese Archivbestānde zu nutzen. Diese Studie stützt sich dahingegen auf zumeist unveröffentlichte Quellen aus dem Public Record Office (London), dem Völkerbundarchiv in Genf, den Akten des Auswärtigen Amtes einschließlich der Berichte seiner Wiener Pressestelle während des Zweiten Weltkriegs (aus dem Münchner Südost-Institut), den Beständen des Instituts für Zeitgeschichte in München und den National Archives in Washington.

Bis 1947 erschienen in Rumānien mehrere Publikationen, die Archiv- und statistisches Material zur Judenproblematik aufarbeiteten oder daraus zitierten. Das bekannteste ist das dreibändige Schwarzbuch von Matatias Carp, das in den Dokumentationen der United Restitution Organization (URO) vielfach verwertet wurde. Auch dieses Material ist als Quelle infolge verwehrten Zugangs zu Rumāniens Archiven noch nicht nachprüfbar. Da das Schwarzbuch in politischer Absicht geschrieben wurde, ist kritisches Benutzen angezeigt. Gleiches gilt für die verschiedenen Erlebnisberichte, die oft erst viele Jahre nach den Ereignissen verfaßt wurden, wenngleich diese Berichte für die Klärung mancher Detailfragen, zu denen die eigentlichen Quellen schweigen, hilfreich sein kōnnen, wie z. B. das von Hugo Gold über die Vorgānge in der Bukowina zusammengestellte Sammelwerk.

Die bisher noch lückenhafte Erforschung der Geschichte der Juden Großrumäniens ergibt eine unbefriedigende Ausgangsposition. Primärforschung fehlt für manche Abschnitte fast gānzlich - Beispiel sei hier eine Skizze jüdischer Geschichte in Binnenrumänien zwischen Herbst 1941 und Ende 1945; für andere Bereiche liegt nur eine stark emotionalisierte Darstellung vor - beispielsweise die grauenvolle Geschichte der Juden in dem an Ungam abgetretenen Nordwestsiebenbürgen. Während über die Vorgānge in der Bukowina anläßlich der Deportation nach Transnistrien aus Erlebnisberichten viel Material verfügbar ist, fehlt es für Bessarabien, dessen Juden ein ähnliches Schicksal ereilte. Eine Untersuchung zur Zahl der jüdischen Opfer während des Zweiten Weltkriegs muß diese beträchtlichen Lücken in der Primärforschung zur Kenntnis nehmen, kann sie aber nicht zugleich auch überwinden. 


\section{Rechtsstatus und Wirtschaftspotential der Juden in der Zwischenkriegszeit}

Die Behandlung der Staatsbürgerfrage der Juden Rumāniens im Zeitraum 1918/1924 sowie 1938/1941 durch Bukarester Politiker und Regierungen erinnert, ebenso wie die Mischung von legalistischen Spitzfindigkeiten und wirtschaftlichen Erwägungen, an die zirkulären Argumentationsmuster rund um die , jüdische Frage ${ }^{\mu}$ im Altrumānien des 19. Jahrhunderts. Altrumänischen Politikem vom Schlage des Parteichefs der National-Liberalen, C. I. Brătianu, fiel es schwer, die von den Großmāchten auf den Pariser Vorortkonferenzen 1919 geforderte Einbürgerung aller auf rumānischem Gebiet lebenden Juden durchzuführen. Das hatten die Siegermāchte nämlich bei Gewährleistung der Territorialansprüche Bukarests zur Bedingung gemacht. Brătianu wußte die Forderung der jüdischen Verbände aller Provinzen Großrumāniens nach kollektiver Naturalisierung der Juden wie auch die darauf zielende ultimative Aufforderung Clemenceaus trickreich zu umgehen. Am 22. Mai 1919 wurde ein Dekret erlassen, das für die individuelle Einbürgerung der Juden durch einen Antrag an die örtlichen Magistrate komplizierte Bedingungen vorsah; am 9. Dezember 1919 wurde der internationale Minderheitenschutzvertrag in Rumānien bekanntgemacht, aber erst am 30. August 1920 durch die Regierung Vaida-Voevod unterzeichnet. Der entscheidende Artikel 7 dieses internationalen Dokuments wurde in die neue rumānische Verfassung 1923 nicht eingebracht. Hier wurde in Artikel 5 lediglich pauschal die Gleichstellung aller Staatsbürger, ohne Unterschied ihrer Geburt, Sprache oder Religion festgeschrieben. Schon nach einem Jahr kam im Monitorul Oficial (23. Februar 1924) ein Bündel neuer Staatsbürgerschaftsbestimmungen für Juden heraus, das Fristen und Stufungen für eine tatsāchliche Einbürgerung vorschrieb und etwa einem Fünftel der in Rumānien bereits naturalisierten Juden die Staatsbürgerschaft wieder entzog. 16

Zu den Hintergründen gehört einerseits die Tatsache, daß nach der Revolution im benachbarten Rußland vor allem in den östlichen Landesteilen viele jüdische Flüchtlinge in das Land geströmt waren. So wurden bereits 1919/1920 in der Bukowina etwa 40000 Juden nicht eingebürgert. 17 Fluktuation von Juden in beiden Richtungen an Rumäniens nordōstlichen Grenzen hatte es wirtschaftsbedingt zumindest seit dem 18 . Jahrhundert gegeben. ${ }^{18}$ Altrumānien hatte darauf insofern positiv reagiert, als es reli-

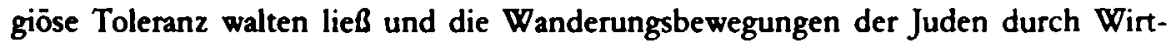
schaftserlasse zu regeln versuchte, ihnen jedoch nach dem Wegfall der Privilegien und Schutzbestimmungen für ,ausländische Residenten“ im 19. Jahrhundert nur den min-

16 Enc. Jud, Bd. 14, Sp. 390, 395; Gold, Geschichte Bukowina, Bd. 2, S. 3-6; PRO, FO 371 - 7701 - 106904, C 4083 (Dering am 11.2.1922) f. 59.

17 Enc. Jud, Bd. 14, Sp. 394.1924 sollen in Großrumänien etwa 150000 Juden wieder staatenlos gewesen sein.

18 Cohen, Seeds, S. 6 f.; Enc. Jud, Bd. 4, Sp. 1477; Jüdisches Lexikon in 4 Bänden, Berlin (1930), Bd. 1, Sp. $1223 \mathrm{ff}$. Für die Geschichte der Juden Rumāniens wurde eine Quellenedition in rumānischer Sprache begonnen, in der verstreut liegende Texte vom 14. Jahrhundert bis 1750 erstmals zusammengeführt sind: Victor Eskenasy/Mihail Spielmann (Hrsg.th Izvoare şi mārturii referitoare la evreii din România. 2 Bde., Bucureşti 1986 und 1988. 
deren Rechtsstatus von „Fremden“ oder „Untertanen“ zubilligte. ${ }^{19}$ Im Gegensatz zu jenen in Altrumānien, die vor 1918 nur vereinzelt volles Staatsbürgerrecht besaßen, waren die Juden der Habsburger Monarchie (also auch in der Bukowina, Siebenbürgen, dem Banat, der Marmarosch und dem Kreischgebiet) seit 1848 Vollbürger, die Juden Bessarabiens immerhin seit 1917.20 Altrumänien hatte alle Bestimmungen internationaler Verträge zur Naturalisierung der Juden seit dem Artikel 44 der Akte des Berliner Kongresses als ,Einmischung in innere Angelegenheiten' zu umgehen verstanden. ${ }^{21}$

Die Uberprüfung der Bestimmungen zur Einbürgerung von Juden aus dem Jahr 1924 nahm am 21. Januar $1938^{22}$ ein neuerliches Gesetz zur "Revision der Staatsbürgerschaft “ wieder auf. Begründend wurde angeführt, in Rumänien lebten viele Juden, die sich die rumānische Staatsbürgerschaft erkauft oder erschlichen hätten. ${ }^{23}$ In der rumānischen Presse zirkulierten damals überhöhte Angaben über die Zahl der Juden im Lande, und die Minderheitsregierung Goga-Cuza versuchte mit diesem Dekret, politisch mehr Rückhalt zu erlangen. Premier Goga hatte das plumpe Konzept bereits am 2. Januar 1938 in einer Regierungserklärung auch der intemationalen Presse bekanntgegeben. Die nach 1918 den Juden erteilte Staatsbürgerschaft sei zu überprüfen: “... par centaines de milliers (l'élément sémite) a envahi la Roumanie où s'installait par désir de gain et grâce à la corruption et à la fraude. ${ }^{44}$ Die Maßnahme lōste, eher unerwartet, zahlreiche diplomatische und wirtschaftliche Aktionen aus. Der Verband der Juden Rumāniens richtete Petitionen an die internationalen jüdischen Organisationen, an Frankreich und Großbritannien; der Dreierausschuß beim Völkerbund beschäftigte sich mit der Judenfrage in Rumānien. ${ }^{25}$ Die jüdische Wirtschaft ihrerseits traf in Rumänien Boykottmaßnahmen, die ihre Wirkung nicht verfehlten. ${ }^{26}$

Dieser erste Versuch einer Einbeziehung antisemitischer Elemente in die Innenpolitik scheiterte mit dem Fiasko der Regierung Goga-Cuze, die bereits im Februar 1938 durch einen königlichen Staatsstreich abgelöst wurde; die westlichen Schutzmāchte Rumāniens und der Völkerbund sahen mangels konkreter Falldarstellungen von einer

19 Cohen, Seeds, S. 11-14; Enc. Jud. Bd. 14, Sp. 387-393. Vgl. dazu eine erste gründliche Arbeit von Beate Welter, Die Judenpolitik der rumänischen Regierung 1866 - 1888, Frankfurt 2. M. 1989.

20 Enc. Jud., Bd. 14, Sp. 393; Bd. 4, Sp. 703 u. 1477; Bd. 15, Sp. 1342.

21 Cohen, Seeds, S. 4 f.; Enc. Jud, Bd. 14, Sp. 389.

22 Pantelimonescu, Statutul, Dekret-Gesetz Nr. 169 vom 21.1.1938 (MO Nr. 18 vom 22.1.1938), S. 16-27: Binnen 30 Tagen sollten alle Bürgermeister Listen sämtlicher in Nationalitätenregister eingetragenen Juden veröffentlichen (Art. 5) und diejenigen löschen, die erst nach den festgesetzten Stichtagen eingetragen worden waren.

23 PRO, FO 371 - 22351 - 106834, R 10249, f. 287 und 96; LNA R 3943 - 4/32402/13396 (Petition Jarblum, 13.1.1938), S. 1-8, bes. S. 41.

24 LNA, ebenda, S. 24, aus der programmatischen Rede Octavian Gogas, die am 2.1.1938 in der Zeitung „Universul ${ }^{4}$ erschien.

25 Das gesamte Paket an den Vōlkerbund umfaßt 4 Petitionen und ein Zusatzschreiben aus dem Zeitraum 13.1. - 12.2.1938. Inhalulich sind diese Schriften identisch, das Material stammt offensichtich von gut informierter Seite aus Rumänien. Die erste Klageschrift entsandte das Exekutivkomittee des Jüdischen Weltbundes (mit 5 langen Anhängen), dann folgten als Absender die Alliance israélite universelle, das Joint Foreign Committee of the Board of Deputies of British Jews and the Anglo-Jewish Association und (in gleicher Ausstattung wie die erste) eine Petition seitens des Comité pour la défence des droits des Isrélites en Europe centrale et orientale (vgl. LNA, ebenda, S. 1).

26 Enc. Jud, Bd. 14, Sp. 396. 
offiziellen Démarche in Bukarest bzw. einem Völkerbundvotum ab. ${ }^{27}$ Ähnliches schien man zunāchst auch von den Augustgesetzen Carols II. gehalten zu haben, die Umsetzung in die Praxis erschien unwahrscheinlich. Doch nach dem Thronverzicht des Königs, Anfang September 1940, kamen die Legionāre als Mitbeteiligte an der Militärregierung Ion Antonescus an die Macht und damit sollte sich vieles ändern. Nachdem schon am 9. Juli 1940 ein Dekret den Ausschluß der Juden aus den öffentlichen $\ddot{A}$ tern bestimmt hatte ${ }^{28}$, wurde nun auf die Augustgesetze, die den Rechtsstatus der Juden ins Wanken brachten ${ }^{29}$, zurückgegriffen. Zahlreiche weitere Bestimmungen zur wirtschaftlichen Schwāchung der Juden folgten.

Gegen das seit 1918 gepflegte Selbstverstāndnis Großrumāniens prallten im Sommer 1940 die Revisionsansprüche der Nachbarn, die vom Deutschen Reich diplomatisch unterstützt wurden: Dem Zweiten Wiener Schiedsspruch vom 30. August 1940, der die Abtrennung Nordwestsiebenbürgens beinhaltete, war ein zweiter harter Schlag vorausgegangen - die Sowjetunion hatte am 26. Juni 1940 ultimativ die Abtretung der beiden Ostprovinzen Bessarabien und (Nord-) Bukowina gefordert und sich damit durchgesetzt.

Als Ende Januar 1941 die Legionāre von der Regierung ausgeschlossen worden waren, bedeutete dies nicht das Ende antisemitischer Gesetzgebung in Rumānien; es zeigte sich jedoch noch deutlicher, daß alle gegen Juden gerichteten Gesetze und Maßnahmen regional unterschiedlich gehandhabt wurden. Im Osten des Landes wurde eine härtere Gangart an den Tag gelegt und nach der Rückeroberung Bessarabiens und der nördlichen Bukowina wurden Sondergesetze mit regionaler Reichweite erlassen. Dazu gehörten auch Erlasse gegen die Juden. ${ }^{30}$ Ähnliches läßt sich im Bereich wirtschaftlicher Maßnahmen beobachten. Sie wurden als allgemeingültig verkündet, aber regional selektiv angewandt. Nachdem spātestens mit der Weltwirtschaftskrise die Modernisierungspolitik der National-Liberalen Partei gescheitert war ihr ideologisches Kennzeichen war das nationalrumänische „Durch-uns-selbst “31 begann in Bukarest die Suche nach geeigneten Sündenböcken für fehlgelaufene oder ausgebliebene wirtschaftliche Entwicklungen und verletzte nationale Gefühle. Die Minderheiten im allgemeinen wurden dafür verantwortlich gemacht, die Juden unter diesen wiederentdeckt; in Altrumānien waren sie die einzige große Minoritāt gewesen.

27 LNA, ebenda, S. 1. Eine Vortage des Foreign Otfice vom 2.5.1938 bestätigh, daß Dr. Filderman namens des Verbandes der Juden Rumäniens die von ihm initiierten, gegen die antisemitischen Gesetzesvorschläge der Regienung Goga gerichteten Petitionen auf Eis legen ließ, da sich die Lage unter der Königsdiktatur entspannt und die Grolmächte erfolgreich in Bukarest intervenient hätten. (PRO, FO 371, 22349 - 106834, 1. 173 r, v; ebenda, 22351 - 106834, f. 196, 198; ebenda, 22350 - 106834, f. 228 v.)

28 Text bei Pantelimonescu, Statutul, S. $67 \mathrm{ff}$, Erläuterungen S. 69-76. Vgl. auch Hillgnuber, Rumänisch-deutsche Beziehungen, S. 237, über die Anwendung dieser Dekret-Gesetze.

$29 \mathrm{Vgl}$. Anm. 11. Das neue Dekret-Gesetz bestimmte die "einheitliche und entschlossene Regelung der Judenfrage" und legte fest, wer Jude sei (Pantelimonescu, Statutul, S. 48 f.), schloß Juden vom Heeresdienst, von freien Berufen und Bereichen der Offentlichkeit aus (ebenda, S. 49-65).

30 Einige dieser gegen Juden erlassenen Sondergesetze für die Bukowina sind bei Gold, Geschichte Bukowina, Bd. 2, S. $49 \mathrm{ff}$, veröffentlicht. Besonders zu erwähnen sind die Verordnung über die „Öffentliche Ordnung und Sicherheit" Nr. 1344 vom 30.7.1941 und die "Verordnung Nr. $23^{\text {“ }}$ betreffend das jüdische Gerneinschaftsleben in den Ghettos und Lagem Transnistriens vom 11.11.1941.

31 Vgl. eine Darstellung dieser Zusammenhänge bei Krista Zach, Agrarsozialer Wandel in Rumānien und Jugoslawien als Beispiel einer Modemisienung in Südosteuropa (1918-1980), in: Jahrbücher f. Gesch. Osteuropas 4 (1988), S. 504-529, hier 507-511. 
Im benachbarten Ungarn hatte sich Ähnliches nach den Territorialverlusten und Prestigeeinbußen am Ende des Ersten Weltkriegs 32 ereignet.

In Rumānien, dessen Politik bis dahin keine aggressive Minderheitenfeindlichkeit gezeigt hatte, erschienen seit 1934 Gesetzesverordnungen und -dekrete zur Förderung der "Rumānisierung": Ein numerus ralacbicus sollte nunmehr bei der Zulassung zum Hochschulstudium, für Staatsämter und in wichtigen Industriebetrieben angewandt werden, wurde aber - wie meist in diesem Lande - auch geschickt umgangen. ${ }^{33}$ Diese Verordnungen galten in den dreißiger Jahren für alle Minderheiten Rumāniens, sie trafen aber bereits damals schon besonders die Juden. Im Zeitraum von 1940 bis 1944 befaßten sich die für "Rumänisierung“ zustāndigen Einrichtungen ausschließlich mit jüdischen Vermögensangelegenheiten.

Die Entstehung und Entwicklung dieser Institutionen für "Rumānisierung “ können nicht aus einer ideologischen oder tagespolitisch bedingten Nachahmung faschistischer Vorbilder erklärt werden, wenngleich in den vierziger Jahren die bloßen Namen und vor allem die Zielgruppe der Juden das nahelegen. Auch hier bedarf es eines Rückblicks in die Geschichte der Juden Altrumäniens einerseits wie der Einbeziehung gesamtwirtschaftlicher Aspekte andererseits. Rumänisches Gedankengut des 19. Jahrhunderts - im übrigen ebenso auf Griechen angewandt - rezipierend, lautete die Kurzformel dafür in etwa folgendermaßen: Schon immer hätten die Juden eine nationale Entwicklung der Rumānen beeinträchtigt und die Entfaltung rumānischer Wirtschaftskraft behindert ${ }^{34}$, für Rumāniens Wirtschaft seien sie jedoch unentbehrlich. ${ }^{35}$ Das Paradoxe dieser Aussage bedarf keines weiteren Kommentars. Die Judenpolitik der vierziger Jahre wurde in Rumānien durch Widersprüche solcher Art geprāgt. Antijüdische Vorurteile und unklare Rechtsnormen im Hinblick auf den staatsbürgerlichen Status der Juden kennzeichnen das Bild ebenso wie die wirtschaftlichen Freiräume, die ihnen der Staat fallweise gewāhrte, bzw. versperrte. Scheinbar waren also auch die beiden Bereiche Wirtschaft und Zivilrecht seit dem 19. Jahrhundert miteinander verquickt.

Die konzeptionelle Unsicherheit rumānischer Regierungen in der Judenfrage seit etwa 1860 wird dadurch unterstrichen, daß Gesetze und Erlasse in ihrer Wirksamkeit nicht überschātzt werden dürfen. Normierungen dienten oft allein außenpolitischer Absicherung; die Möglichkeiten der Umgehung oder Ausnahmeregelung waren in Rumānien immer schon vielfältig und erfolgversprechend gewesen. Deswegen genügt

$32 \mathrm{Vgl}_{\mathrm{g}}$. Fischer, Entwicklungsstufen, S. $132 \mathrm{f}$

$33 \mathrm{Vgl}$. z. B. den Bericht des britischen Konsuls Elphick in Klausenburg, PRO, FO 371-16818, C 8065 f. 209-211 (29.8.1933)

34 Diese wiederkehrende Argumentation zieht sich zwar unbewiesen, aber doch als ideologisches Kontinuum durch die Geschichte der rumänisch-jüdischen Beziehungen seit mindestens der Mitte des 19. Jahrhunderts und führt als Urheber etwas mißverständlich Fürst Karl von Hohenzollem (den späteren König Karl I.) an. $V_{g} 1$. Cohen, Seeds, S. 2 f. und neuerdings Welter, Judenpolitik. Selbst Carol II. spielte in einem Interview für den "Daily Herald" vom 10.1.1938 darauf an: "It cannot be denied that there is a strong anti-semitic feeling in the country. That is an old question in our history." (LNA, R 3943, 4/32402/13396, Annex II, S. 27). Ion Antonescu nimmt dieses Motiv in seinem Tagesbefehl vom 5.7.1941, nach dem Pogrom von Iaşi, wieder auf. Vgl. Archiv des Instituts für historische und politische Wissenschaften in Buknrest (Institutul de ştiinf̧e istorice şi politice, im folgenden: Artiva Isisp), fond XXIV, dosar 331, f. 7. (Für die Quelle sej Lerry Watts, Los Angeles, gedankt).

35 Vgl. den Bericht Farquars an das Foreign Office vom 10.8.1938: PRO, FO 371, 22350 - 106834, R 7054, f. $158 \mathrm{f}$. 
bei der Beschäftigung mit diesem Aspekt rumänischer Geschichte die positivistische Betrachtung normativer Bestimmungen durchaus nicht. Gerade in der Judenpolitik kōnnte sie zu Verzerrungen einer ohnehin komplexen Sachlage führen. Es wäre schließlich zu fragen, warum ein junger Nationalstaat wie Rumānien während der Zwischenkriegszeit versuchte, seine vielfältigen Probleme mit der Wirtschaftsentwicklung, Versorgung, technischen Modernisierung, mit der Ausbreitung des Nationalstaatsgedankens und seinen zahlreichen Minderheiten zu verlagern oder zu verdrängen, indem er sich zunehmend intensiver mit einer Minderheit im besonderen befaßte: mit den Juden, ihrer Gesamtzahl, ihrer Einbürgerung, ihrer Loyalitāt zum Staat etc. Diese Politik sollte darauf abzielen, einen Teil dieser Minderheit loszuwerden, sei es durch Ausbürgerung, durch erhoffte internationale Umsiedlungsaktionen ${ }^{36}$, schließlich durch Deportation, wirtschaftliche Ausplünderung und Begünstigung der Auswanderung. Jedes dieser Konzepte wurde erprobt, der große Exodus der Juden aus Rumānien nach dem Zweiten Weltkrieg brachte schließlich den zweifelhaften „Erfolg ${ }^{\star 3} .37$

Bukarest verfolgte bezeichnenderweise seit der Weltwirtschaftskrise eine minderheitenfeindliche Politik, die zunehmend antijüdische Akzente erhielt. Kultureller und zivilrechtlicher Beschränkung folgte die wirtschaftliche Auspressung. Letztendlich führte diese Politik zur Abschiebung der ostrumänischen Juden nach Transnistrien, aber auch zur Verschonung der binnenländischen Juden aus finanziellen und seit 1942/43 aus außenpolitischen Erwägungen. Die politische Entwicklung hatte ab 1940 die antisemitische Zielrichtung verschärft. Aus einer rumānischen Judenpolitik, die bis dahin in einem internationalen, vōlkerrechtlich geschützten Rahmen verlaufen war, wurde - gefördert durch den vom Dritten Reich bestimmten Trend - eine regionale, innerrumänisch determinierte Judenpolitik mit verschiedenen Akzenten je nach Landesteil. Diese Regionalisienung verlief in drei Etappen - Sommer 1940, 1941 und 1942 - und mit unterschiedlichen inhaltlichen Aspekten.

\section{Regionalisierungsaspekte in Rumäniens Judenpolitik}

Hatten alle bis zu den Augustgesetzen Carols II. von rumānischen Regierungen ergriffenen antijüdischen Maßnahmen oder Gesetzesintentionen eine beträchtliche internationale Anteilnahme erfahren, mit der Folge, daß wenig vom Beabsichtigten in die Tat umgesetzt wurde, zeichnete sich nun eine Wende ab. Sie wird allgemein dem sich verstärkenden deutschen Einfluß auf Rumänien zugeschrieben. Aber der Umschwung

36 In der offensichtlichen Zwangslage, in die die Judenpolitik Rumàniens im Jahre 1938 geraten war, trugen sich manche Politiker und auch König Carol II. mit dem Gedanken an eine internationale Regelung in Sachen Wohnstätte für statenlos gewordene Juden aus Europa. Im Falle Rumäniens standen nicht nur die jüdischen Flūchtlinge aus der Sowjetunion zur Debatte (die 1917/1918 gekommen waren), sondern auch die aus Polen und dem Deutschen Reich sowie auf damals numänischem Stantsgebiet ansässige Juden, die die Optionstristen verpabt hatten. Laut einem Bericht des Verbandes der Juden Rumäniens an den Völkerbund waren das 1938 zusammen nur einige Tausend (LNA, R 3943, 4/32402/13396, Annex I zur Petition des Jüdischen Weltbundes, S. 9 ff.). Die erhoffte amerikanische Hilfe für Umsiedlungsmaßnahmen und die Unterstūtzung durch internationale Fonds blieb aus.

37 Vgl. genauere Angaben dazu in: Krista Zach, Die Juden Rumäniens zwischen Assimilation und Auswanderung. Eine Minoritīt im Verschwinden, in: Deutsche und ungarische Minderheiten im Donauraum, München 1991. (Im Druck.) 
kam nicht allein dadurch zustande und ist ebensowenig dem Desinteresse der bisherigen Protektoren der jüdischen Menschenrechte in Rumänien - den Westmächten, dem Völkerbund (bis zu Rumāniens Austritt 1940), den internationalen jüdischen Verbānden - zuzuschreiben. ${ }^{38}$ Die zunehmende Gefährdung der Juden Europas hatte Wirkungen auch auf die Handlungsweise des Verbandes der Juden Rumäniens und seines Prāsidenten Dr. Filderman, der nun vermehrt auf Diskretion und Geheimabsprachen mit Regierungschef Antonescu setzte. Da die Quellen fast keine direkten Aussagen darüber hergeben, kann diese Umorientierung nur indirekt erschlossen werden. Die Bukarester Judenpolitik bestand in Absprachen über enorme wirtschaftliche und fiskalische Beiträge der Juden Rumāniens zum Kriegsaufkommen und in der damit erkauften weitreichenden physischen Verschonung der Juden vor antisemitischer Verfolgung. ${ }^{39}$ Vielleicht blieben deswegen auch die Anstrengungen des Reichssicherheitshauptamtes (RSHA) und namentlich des Judenberaters“ in Bukarest, SS-Hauptsturmführer Gustav Richter, hinter der Fassade von Gesetzeswerken und Maßnahmenkatalogen stecken, ohne tatsāchlichen Einfluß auf Antonescus Judenpolitik zu erlangen. Die wortreichen Berichte Richters, die er vom Zentralamt für Rumānisierung übernahm - es bestand seit dem 3. Mai 1941 und verwaltete das enteignete jüdische Vermōgen -, kōnnen über seine tatsächliche Einflußlosigkeit nicht hinwegtāuschen.

Es ist erstaunlich, daß gerade die Augustgesetze zum Verbot der Mischehe (8. August 1940) sowie zur Definition und staatsbürgerlichen Einordnung der Juden Rumäniens (9. August 1940)40 diese Wende markieren. Bukarest schien damit voll auf den in Berlin erwünschten Kurs in der Judenfrage einzuschwenken; man darf aber die Alibifunktion dieser Gesetze und die rumänische legalistische Praxis in der Judenfrage nicht übersehen. Die Augustgesetze gaben den nach außen vertretbaren und nach innen genügend dehnbaren Rahmen für die bereits skizzierte Politik; sie blieben von August 1940 bis August 1944 in Kraft. Auf diesem sehr brüchigen Boden konnte sich künftig die Judenpolitik bewegen. Sie sollte aber immer die nicht von den Nationalsozialisten diktierte Politik Rumāniens und im rumānischen Staatsinteresse bleiben.

Die Grundlage der künftigen rumänischen Judenpolitik bildete das Gesetz vom 9. August 1940, daher sei der Inhalt in seinen staatsbürgerlichen Bestimmungen kurz erläutert. Die Juden Rumäniens wurden nach der Dauer ihrer Zugehōrigkeit zu Rumānien und ihrem zivilen Status gegenüber Rumänien wie folgt eingeteilt: Die 1. Gruppe war am besten abgesichert, sie umfaßte die schon vor dem 30. Dezember 1918 in Altrumānien Eingebürgerten oder Frontkämpfer (mit ihren Nachkommen und Ehepartnern). Hier handelte es sich um etwa 10000 Juden. Die 2. Gruppe umfaßte die sehr viel zahlreicheren Juden Altrumāniens, die am Stichtag kein volles Bürgerrecht besaßen. Die 3. Gruppe schloß alle anderen Juden ein, nämlich die der neuerworbenen Territorien Bukowina, Bessarabien, Siebenbürgen, Banat, Kreisch-Marmarosch sowie alle spāter als zum 30. Dezember 1918 Eingewanderten. Ihnen sollten in

38 Vgl. Anm. 25.

39 Da der fehlende Zugang zu rumänischen Archiven eine genauere Auflistung dieser Sondersteuem erschwert, kann nur auf die in Anm. 13 und 14 erwihnten Angaben zurückgegriffen werden. Angaben über sog. Wehrsteuem vgl. in Anm. 42.

40 Zum Verbot der Mischehe, Deltret-Gesetz Nr. 2651, vgl. Pantelimonescu, Statutul, S. 67-76 (mit Kommentar) und NA 871.4016/240, S. 1-7. 
der Folgezeit die meisten Lasten auferlegt und der geringste Schutz des Staates gewāhrt werden. Mit gewissen Modifizierungen kehrte Bukarest damit zu den Intentionen altrumänischer Judengesetzgebung zurück.

Es folgten eine Reihe weiterer Gesetze und Bestimmungen: Enteignung des lāndlichen Grundbesitzes (4.10.1940), des Waldbesitzes (12.11.1940), der Schiffe (3.12.1940), des städtischen Grundbesitzes (27.3.1941), Berufsbeschränkungen in Presse, Film und Verleih, Entzug von Lizenzen für Gewerbetreibende und von Zulassungen für Anwälte, Ärzte, Hochschullehrer etc. ${ }^{41}$ Wie sich zeigen sollte, konnten sich Vermögende von vielen Bestimmungen freikaufen. Das galt auch für den Militär- bzw. Arbeitsdienst. Ein Gesetz vom 4. Dezember 1940 schloß alle Juden aus der Armee aus und verpflichtete die Wehrdienstpflichtigen wie alle anderen tauglichen Mānner zwischen 18 und 50 Jahren ersatzweise zum Arbeitsdienst. 42 Dazu wurde ein Jahr spāter ein Ausführungsgesetz erlassen ${ }^{43}$, doch zeigen die am 27. Juni 1942 und am 14. September 1942 beim Großen Generalstab veröffentlichten Durchführungsbestimmungen, wie schwierig die organisatorische Umsetzung dieser Gesetze für die Verwaltung gewesen sein muß. Das Zentralamt für Rumänisierung war damit überfordert: „Dem Befehl des Herm Marschalls Antonescu Nr. 5295 M vom 21.4.1942 gemäß erhielt der Große Generalstab die Aufgabe, die Arbeitsdienstpflicht der Juden zu organisieren, zu kontrollieren und zu überwachen. Die Aufgabe des Zentralamtes für die Rumānisierung beim Unterstaatssekretariat für Arbeit ist es, die personelle Seite der Rumānisierung durchzuführen, und zwar durch die stufenweise Entfernung und Ersetzung der Juden aus dem Wirtschaftsleben des Landes. Diese beiden Institutionen müssen zusammenarbeiten, damit die Einzelaktionen mit Blick auf das gemeinsame Ziel harmonisiert werden kōnnen. ${ }^{44}$ Dieses Zitat macht den Unterschied zwischen Gesetzeserlaß und -wirklichkeit deutlich. Es gab zwar den Arbeitsdienst für Juden in Rumānien, aber keine umfassenden gesetzlichen Bestimmungen dafür. Primärforschung muß auch hierzu die Einzelheiten klären, einschließlich der Möglichkeiten der Befreiung vom Arbeitsdienst.45

41 Broszat, Gutachten, S. $115 \mathrm{ff}$.; Hilberg, Destruction, Bd. 1, S. $488 \mathrm{ff}$; NA (F. P. Hibbard am 23.8.1940) $871.4016 / 240$.

42 Der "militärische Sutus“ der Juden Rumäniens wurde in dem Dekret-Gesetz Nr. 3984 (4.12.1940) in 15 Artikeln festgelegt; dem folgten in einem weiteren Dekret-Gesetz vom 20.1.1941 Bestimmungen über "Militirsteuem", d. h., die wehrpflichtigen Minner hatten, ebenso wie alle wehrfihigen Juden bis zum S0. Lebensjehr, sogenannte Wehrsteuem prozentul zum jeweiligen Steuersatz des einzelnen und nach der entsprechend testgesetzten Verhältnismäligkeit an den Stat zu entrichten. Dazu sollte, nach entsprechender gesetzlicher Regelung, der Arbeitsdienst treten (Texte bei Pantelimonescu, Statutul, S. 161-177). Diese Bestimmungen wurden später zur Ersatzleistung der Juden für den „Heiligen Krieg" im Osten erklört.

43 Die „Allgerneinen Bestimmungen Nr. 55900 vom 27.6.1942 bezüglich der Abeitspflicht der Juden“ nehmen auf des Detret Nr. 2090 vom 14.7.1941 Bezug, vgl. Arhiva Isisp, fond XXTV, doser 3312, S. 1. Diesen Allgemeinen Bestimmungen wurden am 14.9.1942 in einem Anhang $A$ Etläutenungen und Ergänzungen" in viel größerem Umiang angefügt, vgl. ruminischen Text (Drucksache) aus den Bestīnden der NA, RG 226 Reconds Office Strat. Serv. Aus diesen geht hervor, daß die Behörden vielschichtige organisatorische Schwierigkeiten bei der Durchführung des Arbeitsdienstes hatten; die Möglichkeit, eine finanzielle Ablösung der Atbeitspflicht ru schaffen, schien unvermeidlich.

44 Aus "Ertäuterungen und Ergänzungen", NA, ebend, S. 5 (Ubers. d. Verf.)

45 Zahlreiche Hinweise auf diesen "Freikauf" sammelte G. Richter bei der Deutschen Gesandtschaft aus Presse und Ministerialquellen, offenbar aber auch aus eilfertig von Informanten gelieferten denunziatorischen Berichten, die die deutschen Regionalkonsulate (in Temeswar, Kronstadt, Czemowitz, Galapi) erhielten. Aus der Zeit zwischen dem 9.8.1940 und dem 30.11.1941 vurden daraus unfassende Auflistungen Antijüdische(r) Maßnahmen" zusammengestellt (IIZ, MA 1538/2). Mangels konbreter Daten folgten darauf 1942 und 1943 Klagen über die Nichtanwendung der antisemitischen Gesetzesbestimmungen. Ein als 
Durch die zunehmende Enteignung jüdischer Vermögenswerte wurden dem Zentralamt für die Rumänisierung zwar beträchtliche Kapitalwerte ${ }^{46}$ zugeführt; das know how jüdischer Gewerbetreibender und Industrieller ließ sich damit aber nicht einfach ersetzen. Die seinerzeit von der Regierung Goga-Cuza ausgegebene und begeistert in den Medien aufgegriffene Parole „Rumānien den Rumänen“ war 1942 zwar gesetzlich verankert, damit aber nicht realisierbarer geworden. In seiner Regierungserklärung vom 6. September 1942 führte Mihai Antonescu unter der hochtrabenden Uberschrift "Stolz und siegesgewiß" aus: „Um auch auf geschichtlichem Gebiet die Verteidigung unseres Volkes fortzuführen, hat Marschall Antonescu den rumänischen Besitz von der fremden Uberwucherung befreit.. Zur Rumānisierung des Wirtschaftslebens wurden Einschränkungsmaßnahmen gegenüber Juden und Ausländern und Unterstützungsmaßnahmen für das rumänische Element durchgeführt, indem Unternehmen und Vermögensbestimmungen von Juden und Ausländern kontrolliert werden. Bisher wurden 2000 Unternehmen unter Kontrolle gestellt. ${ }^{\text {"47 }}$ Dieses Zitat und die genannten Vermögenswerte belegen aber, daß der Stant die Juden massiv zur Kasse gebeten hatte, ohne auf ihre Mitwirkung in der Wirtschaft verzichten zu können. Genauer beschreibt ein Bericht des Wirtschaftsamtes der Deutschen Volksgruppe vom September 1942 die Entwicklung: Wāhrend der kurzen legionāren Regierungsbeteiligung 1940/41 waren "Arisierungs"-Maßnahmen durchgeführt worden; danach fand die $\mathrm{Pa}$ role "Rumänien den Rumānen" in "Rumänisierungs"-Maßnahmen Niederschlag wie Schaffung eines Nationalen Rumänisierungszentrums (Dekret vom 4.3.1941) und eines Unterstaatssekretariats für Rumänisierung (Dekret vom 3.5.1941). Von "Arisierung " war keine Rede mehr. 48

\section{Die Zuspitzung der Lage im Jahre 1941 - Pogrome und Kriegsbeginn}

In einer Atmosphäre öffentlicher Hetze gegen die Juden in der Rechtspresse und antijüdischer Gesetzgebung im National-Legionären Rumānien konnte das Judenmassa-

"Vertraulich" gekennzeichneter Brief des Deutschen Konsulats in Temeswar vom 10.3.1943 gibt dariber Aufschluß: "Trotz aller gegen sie /die Juden/ erlessenen, in der Praxis aber nicht durchgeführten Mafnahmen der ruminischen Regierung haben sie auch heute noch den gröbcen Teil der wiruchaftlichen Schlüsselstellungen inne. Durch Bestechungen und andere unleutere Mittel ist es zum mindesten den Vermōgenden unter ihnen gelungen, sich von jeder Arbeitsleistung und Kontrolle treizumachen... (Sie haben) Einfluß bei fïhrenden ruminischen Persönlichkeiten gewonner, von denen ohnedies mancher - nach formeller Ubernahme ehemaliger jüdischer Unternehmungen - mit ihnen die gleichen finanziellen Interessen teilt Die Juden haben es geschickt verstanden, die Ruminen von ihrer wirtschaftlichen Unentbehrlichkeit zu überzeugen..." (IR, MA 1538/3 und MA 1538/4)

46 Die Summe von 2016482959 Lei wird in Unterlagen der Deutschen Gesandtschaft erwihnt (IF, MA 1538/4 B IV-C1, Regienungserklinung S. 3) Matatios Carp gibt als inoffizielle Schadensziffer Lei 70687849734 an, Quelle ist die Zeitschrift Coment si industric (Oktober 1943). Diese Angeben sollen hier nur als Beispiel dienen (Mataties Carp. Cartea Neagri - Suferinjele Evreilor din Rominia 1940-1944. 3 Bde, Bucureşti 1946 - 1948, hier Bd 1, S. 21).

47 IfZ, MA 1538/4, Regienungsertlainung v. 6.9.1942, S. 3

48 Die Entfaltung des aus den zwanziger Jahren bekannten ideologischen Postulats, „Ruminien den Rumanen“ , dem die Regierung Goga einen spezifisch antijüdischen Akzent vertieh, vgl. z. B. NA 871.4016 Jews 87 (enclosure to dispatch 347 vom 14.1.1938), sollte hier nur skizziert werden. Zum Bericht der Volksgruppe vgl. Reinerth, Die Deutschen, S. 244 f., der in Politischen Archiv unter Inland II D, Vorgang 62-15 zum 23.10.1942 aufbewahrt wird. 
ker beim Putsch der Eisernen Garde Horia Simas vom Januar 1941 noch als bedauerlicher Exzeß irregeleiteter Jugendlicher erscheinen. In Bukarest kam dabei eine unbestimmte Zahl - bis zu 700 - Juden um. ${ }^{49}$ Die Judenmassaker großen Ausmaßes im östlichen Landesgebiet aber, zu denen es zu Beginn des Ostfeldzuges kam, lösten im Binnenland Schrecken und Proteste aus. Sie begannen mit dem Pogrom in Iaşi am 29. Juni 1941, dem weitere Greuel und Morde an Juden folgten. Die Zahl der Opfer wird zwischen 3233 und 10000 angegeben.50 Danach kam es auf dem Vormarsch über die Pruthlinie nach Bessarabien und der Bukowina durch das rumanische Heer, aber auch durch Zivilpersonen, zu einer Reihe von Pogromen, denen nach vorsichtiger Schātzung wenigstens 50000 Juden zum Opfer fielen.\$1 Nicht nur hochgestellte Persōnlichkeiten und diplomatische Vertreter bekundeten gegenüber General Antonescu ihren Abscheu und Protest\$2, er selbst verurteilte in einem Tagesbefehl vom 5. Juli 1941 die Vorfäle scharf und verlangte die Bestrafung der Tater: „Die vor einigen Tagen in Iaşi vorgefallenen Ordnungswidrigkeiten haben Heer und Behörden in ein völlig ungünstiges Licht gebracht. Es war eine Schande für die Armee, daß sie sich bei der Evakuierung Bessarabiens [August 1940] von den Juden beleidigen und angreifen ließ, ohne darauf zu erwidern. / Viel größer ist aber die Schande, wenn Soldaten, nur um zu plündern und zu mißhandeln, aus eigener Initiative die jüdische Bevōlkerung angreifen und blindlings morden wie es vor einigen Tagen in laşi der Fall war. / Das jüdische Volk hat den Armen das Brot weggegessen, hat spekuliert und einige Jahrhunderte lang die Entwicklung des rumänischen Volkes verhindert. Es steht außer Diskussion, daß wir uns von dieser Plage des Rumänentums befreien müssen, aber allein der Regierung steht das Recht zu, die notwendigen Maßnahmen zu ergreifen. / Diese Maßnahmen werden bereits angewandt und nach von mir zu bestimmenden Normen fortgesetzt. / Es ist nicht zulässig, daß sich jeder Bürger oder jeder Soldat anmaßt, das jüdische Problem durch Plünderungen und Morde eigenhāndig zu lösen. "53

Das Klima für eine großräumige Verfolgung der Juden in Ostrumänien und den zurückgewonnenen Provinzen Bessarabien und Nordbukowina war durch den Kriegsbeginn und die Judenverfolgung in ganz Mitteleuropa geprägt worden. Die Juden im Osten Großrumäniens waren schon während der Z $\mathbf{Z}$ wischenkriegszeit als „Bolschewisten " diffamiert worden, die von General Antonescu erwāhnten Vorfälle beim Abzug rumānischer und dem Einzug sowjetischer Truppen waren dann von der Presse auch was Czernowitz betraf - ausführlich dargestellt worden. ${ }^{54}$ Der Krieg Rumäniens gegen die Sowjetunion galt als "Heiliger Krieg", als Vergeltung erlittener Schmach durch das Ultimatum Moskaus vom 26. Juni 1940 und zugleich als einzigartige Gelegenheit, die ethnisch wenig günstige Lage des Rumānentums in den beiden Provinzen

49 Vgl. NA, 871.4016/265 (Gunther, vom 3.7.1941) nach Listen des Verbandes der Juden in Rumänien. Sowohl in Presse- wie Korrespondentenberichten war anfangs von höheren Zahlen der Opfer die Rede, wie später auch bei Carp, Cartea Neagria, Bd. 1, S. 25.

30 Die Zahlen bei Karef̧li/Covaci, Zile însîngerate, S. 104f, der bislang einzigen Untersuchung über Einzelvorginge, und Minuila/Filderman, Regional Development, S. 8 (geschätzt); Carp, Cartea Neagrä, Bd. 1, S. 26: 12000 . Eine Untersuchung zum Pogrom von Jassy/laşi ist angekündigt in: Jean Ancel, The Jassy Syndrome (I) in: Romanian Jewish Studies 1 (1987), S. 33-49, hier S. 33 f.

51 Menuili//Filderman, Regional Development, S. 8 - die dort genannte Zahl ist 49419.

32 IfZ, MA 1538/2 (Sommer 1942)

33 Arhiva lsisp, fond XXIV, dosar 3311, S. 7 .

34 Kereftid/Covaci, Zile însîngerate, S. 29 f, 40 ff.; Gold, Geschichte Bukowina, Bd. 2, S. 14; Bericht der Wiener Pressestelle des Auswartigen Amtes vom 23.7.1940 (Informationsbericht 46, S. 2): SOI Z $3301 \mathrm{E}$. 
durch die Vertreibung der Fremden - Juden und Ukrainer - dauerhaft zu nverbessern “. So können Plāne in diese Richtung die von General Antonescu am 5. Juli 1941 erwāhnten Regierungsmaßnahmen gewesen sein, zumal er am 8. Juli 1941 im Ministerrat gesagt haben soll: „Ich bin für die zwangsweise Umsiedlung des gesamten Judentums aus Bessarabien und der Bukowina, das über die Grenze geworfen werden muß. Ich bin auch für die zwangsweise Umsiedlung des Ukrainertums, das zu diesem Zeitpunkt hier nichts mehr zu suchen hat... In unserer Geschichte gibt es keinen günstigeren Moment hierfür."ss

Im gleichen Sinn soll der Vizepremier Mihai Antonescu bereits am 3. Juli $1941 \mathrm{im}$ Innenministerium erklärt haben: „Wir befinden uns im historisch günstigsten Augenblick ... für eine vōllige ethnische Entfesselung, für eine nationale Revision und für die Reinigung unseres Volkes von allen seiner Seele fremden Elementen... Diese ethnische Reinigungsaktion wird in der Entfernung oder Isolierung aller Juden in Arbeitslagern und anderen Orten bestehen, von woher sie keine schlechten Einflüsse ausüben können, ebenso auch aller anderer Volksfremder, deren Einstellung zweifelhaft ist. Falls es notwendig sein sollte, ... kōnnen die örtlichen Verwaltungen der Provinzen auch Maßnahmen der zwangsweisen Umsiedlung des Judentums wie aller anderen Fremden anordnen, sie über die Landesgrenzen abschieben, da sie in Bessarabien und der Bukowina im Augenblick der dauerhaften Wiederherstellung der nationalen [rumänischen] Rechte dort nichts zu suchen haben." 66 Der Krieg im Osten Rumäniens begann dann mit der massenhaften Vertreibung und Verfolgung der Juden.

\section{Die Kriegsjahre 1941-1944}

Ausgehend vom Territorium Rumāniens in seinen Grenzen von 1939 ergeben sich seit Sommer 1941 regional unterschiedliche Maßnahmen gegen die Juden, anteilsmäBig unterschiedliche Zahlen der Opfer und vier verschiedene Verantwortungsträger dafür.

Im Gebiet des nordwestlichen Rumänien, in dem 1940 über 151000 Juden lebten und das durch den Zweiten Wiener Schiedsspruch 1940 an Ungarn kam, blieb es zunāchst ruhiger als in den neuen rumänischen Provinzen. 1944 aber wurden fast alle dort lebenden Juden nach Auschwitz deportiert, etwa 40000 kamen in deutsche Arbeitslager. Die Zahl der Opfer beträgt über zwei Drittel aller dort beheimateten Juden. 57

In den östlichen Provinzen - Bessambien, der gesamten Bukowina (und z. T. in der Moldau) - wurden über die beschriebenen antijüdischen Gesetze hinaus schärfere Maßnahmen angewandt, wozu die Zivilgouverneure im Ministerrang und verantwortlich nur gegenüber Ion Antonescu auch Sonderbestimmungen erließen. $\mathrm{Zu}$ diesen Maßnahmen gehörten:

55 Zitiert nach Carp, Cartea Neagrï, Bd. 3, S. 92 (Ubersetzung d Verf.)

56 Ebenda, S. 91 (Ubersetrung d Verf.).

57 Vgl. Autstellung, Tabelle 4. 
- die Ubernahme der sowjetischen Vermōgensenteignungen bei Juden,

- die Judenkennzeichnung durch den gelben Stem ab 30. Juli 1941 in der Bukowina,

- die Ubertragung des Staatsbürgerschaftsgesetzes Carols II. (3. September 1941), durch das die Mehrheit der Juden Bessarabiens und der Bukowina praktisch ausgebürgert blieb,

- die Ghettoisienung (ab 8. Juli 1941) in Bessarabien und ab September in der Bukowina, zwecks Deportation nach Transnistrien (ab Oktober 1941).

Am 30. Juli 1941 erließ Zivilgouverneur Riosanu „im Interesse der öffentlichen Ordnung und Sicherheit" erste Sondervorschriften für die Bukowiner Juden, denen am 11. Oktober 1941 die Anweisung folgte, die Czernowitzer Juden im alten Judenviertel festzuhalten. Dann erließ sein Nachfolger C. Catolescu, ebenfalls am 11. Oktober 1941, ein „Règlement " für die Funktionsfähigkeit des damit entstandenen Czernowitzer Ghettos und Strafbestimmungen für alle Zuwiderhandelnden.58 Bald ergaben sich für vermögende Juden Freikaufmöglichkeiten, z. B. durch die Bescheinigungen des Bürgermeisters der Stadt T. Popovici.59

Anfang Oktober hatten die rumānischen Behörden bereits mit dem Abtransport der Juden aus der Bukowina, von Norden nach Süden vorgehend, begonnen, die zumeist mit Güterzügen in die bessarabischen Durchgangslager Edineţ, Secureni und Mărculeşti gebracht und dann über die Dnjestrlinie nach Transnistrien abgeschoben wurden. ${ }^{60}$ Nach langen, qualvollen Fußmärschen oder Zugfahrten, auf denen eine unbekannte Zahl von Juden starb, wurden sie schließlich auf über 100 Ortschaften in Transnistrien verteilt. Diese lagen vornehmlich in den beiden nördlichen Kreisen Mogilew-Podolski und Tulčin, in Dörfern und Kleinstädten, aus denen die einheimischen ukrainischen Juden bereits geflohen, von den deutschen Einsatzkommandos vertrieben oder ermordet worden waren. Der dritte Kreis, weiter südlich gelegen, war Golta. 61 Zuletzt wurden die über 50000 in Czemowitz in das improvisierte Ghetto zusammengedrängten Juden ab dem 22. Oktober 1941 schubweise nach Transnistrien gebracht; nur 17000 bis 20000 Juden blieben - allerdings nicht mehr im Ghetto - in Czernowitz zurück.62

Uber die Ereignisse in Bessarabien sind die Mitteilungen spärlicher. Hier begann die Zusammenlegung der nach Abzug der Sowjets in der Provinz noch verbliebenen Juden gleich zu Beginn des Vormarsches der deutschen und der rumānischen Armeen. Eine Sonderverordnung des neuen Gendarmerieinspekteurs von Kischinew, Meculescu, vom 8. Juli 1941 verfügte die Ghettoisierung, um spāter die Enteignung und Deportation der Juden Bessarabiens mit lāndlichem Wohnsitz zu vereinfachen. Kišinev/Chişinău wurde zum grōßten jüdischen Ghetto, aus dem die Deportation nach Transnistrien am 10. Oktober 1941 begann.63 Von der Deportation waren auch Juden

58 Gold, Geschichte Bukowina, Bd. 2, S. 49 ff. (alle vier Verordnungen in deutscher Ubersetzung).

39 Ebenda, S. 62-69, „Mein Bekenntuis“. Abdruck der Bescheinigungen, ebenda, S. 67.

60 Ebenda, S. 14-18 und passim; Manuila/Filderman, Regional Development, S. 8 f.

61 Hilberg, Destruction, Bd. 1, S. 3741.; vgl. auch Sifruatia evreilor din Transnistria aus Arhiva Isisp, fond XXIV, dosar 3311, S. 1-7 (77-83).

62 Gold, Geschichte Bukowina, Bd. 2, S. 21 und passim; Mānuila/Filderman, Regional Development, S. 8 f.

63 Carp, Cartea Neagri, Bd. 3, S. $92 \mathrm{ff}$. 
dieser beiden Provinzen betroffen, die in Binnenrumānien arbeiteten ${ }^{64}$, und schließlich die des moldauischen Kreises Dorohoi65, in dem besonders viele Juden wohnten.

Nach übereinstimmenden Aussagen der Erlebnisberichte und amtlichen Quellen war diese Deportationsphase die schlimmste gewesen. Nach der schließlichen Verteilung der ostrumānischen Juden auf die kleineren und größeren Orte in Transnistrien begann man sich dort, trotz schwerer Arbeit gegen geringfügigen Lohn, trotz des zeitweiligen Fehlens jeglicher Versorgungsmöglichkeiten, trotz bis Ende 1942 andauemder willkürlicher Erschießungen ${ }^{66}$, irgendwie einzurichten. Bald sollten - nach Abzug vielfacher Gebühren und Schmiergelder - auch Geld-, Kleider-, Medikamenten- und Verpflegungssendungen von den Juden aus dem rumänischen Binnenland nach Transnistrien mōglich werden - die "Transnistrienhilfe", die die Beobachter der Deutschen Gesandtschaft in Bukarest mißbilligend, letztlich aber ohnmāchtig, betrachteten. ${ }^{67}$ Gleiches galt für die seit Herbst 1941 verstärkten Bemühungen, Juden aus Rumānien die Auswanderung zu ermöglichen. Im Jahre 1941 kümmerte sich zunāchst die US-Gesandtschaft darum, danach bemühten sich das Rote Kreuz und die internationalen jüdischen Verbände.68 Sie wurden vor allem nach der neuerlichen Befürwortung der Auswanderung der Juden, insbesondere der in Transnistrien, durch die Regierung Antonescu seit Ende 1942 wieder tätig. ${ }^{69}$ Auch wenn es zu keiner größeren Emigration kommen konnte, weil kaum jemand an der Aufnahme jüdischer Flüchtlinge aus Rumānien interessiert war, fanden doch etliche den Weg nach Palästina oder nach Ubersee. ${ }^{70}$

Schrittweise, beginnend bereits 1941 und 1942, entschloß sich die Regierung Antonescu, die Deportationen nach Transnistrien einzustellen. Eine letzte Gruppe kam im Oktober 1942. Etwa 5000 als politisch unzuverlässig geltende Juden aus Czernowitz und 2135 aus Binnenrumānien wurden in Lager wie Vapniarka und Ladyćin gebracht. ${ }^{11}$ Die anfangs strengen Lebensbedingungen in den Ghettos und Lagem Transnistriens 72 waren inzwischen gelockert worden und die willkürlichen Erschießungen hatten aufgehört. ${ }^{33}$ Aber erst mit dem Zusammenbruch der rumänischen Ostfront im Sommer 1944 kamen viele der Deportierten wieder in die Bukowina und andere zentral gelegene Teile Rumāniens zurück. Sogar die Nachkriegsstatistik von 1956 läßt das noch erkennen (vgl. Tabelle 3).

64 Es wird mehrfach über 600 Bessanbier berichtet, die in Galapi arbeiteten und die von dort nach Balpi deportiert wurden. Brief von W. Filderman an Marschall Antonescu v. 19.10.1941, NA 871.4016/287.

65 Ebenda

$66 \mathrm{Vgl}$. Anm. 61. Eine Besserung trat etwa Ende 1942 ein.

67 Ebende Es wurde eine "Transnistrienhilfe" der binnennumänischen Juden eingerichtet Die Deutsche Gesandtschaft klagte bitter über Devisenschieberei und andere Gesetzeswidrigkeiten im Zusammenhang mit der Transnistrienhilfe, vgl. IfZ, MA $1538 / 3$ und MA 1538/1.

68 Gold, Geschichte Bukowina, Bd. 2, S. 19f.; NA 871.4016/24, f. If.

69 Uber das Internationale Rote Kreuz in Genf, die Jüdische Gemeinde dort, über das Joint Committee u. 2 konnten Schiffe für den Transport rumänischer Juden über das Schwarze Meer angeheuert werden. Die Deutschen versuchten vergeblich, das zu verhindem, vgl. Eichmannprozef, Dok. 571 (24.1.1942), ebenda, Dok. 574 (26.6.1942)

70 NA 871.4016/281 vom 4.11.1941; Eichmannprozel, Dok. 481 (29.2.1943); ebenda, Dok. 184 (9.3.1943).

71 Gold, Geschichte Bukowina, Bd. 2, S. 21 f, 25.

72 Ebends, S. $49 \mathrm{f}_{,}$, Verordnung Nr. 23“ vom 11.11 .1941$.

73 Athiva Isisp, fond XXIV, dosar 3311, S. 2 ( $\mathrm{m}$ sie sind optimistischer, was ihre Zukunft anbetrifft, da die Erschiefungen viel seltener wurden...') 
Rückblickend kann man feststellen, daß die gesamte Problematik der Vertreibung der Juden aus den östlichen Provinzen und das Morden mit dem Abzug der rumānischen Truppen und der Verwaltung aus der nördlichen Bukowina und aus Bessarabien am 30. Juni 1940 begonnen hatte. Darauf berief sich auch Ion Antonescu im Tagesbefehl vom 5. Juli 1941 und in einem offenen Brief an Dr. Wilhelm Filderman, den Repräsentanten der rumānischen Juden. ${ }^{74}$ Damals hatten die Befehlshaber zugelassen, daß sich die Truppe an den Juden vergriff, worauf es zu Massenmorden gekommen war. ${ }^{75}$ Während der einjährigen Herrschaft der Sowjets in Bessarabien und der Bukowina waren Teile der jüdischen Bevölkerung eher kooperationsbereit, und als die Russen im Juni 1941 abzogen, nahmen sie nicht nur diese, sondern auch reiche Juden als Gefangene mit. ${ }^{76}$

Die Vorfalle von laşi, Ende Juni 1941, als anläßlich einer Durchsuchungsaktion jüdischer Wohnungen rumānische Deserteure auf rumänische Truppen schossen ${ }^{77}$, verstärkten in der von der Presse bereitwillig genāhrten öffentlichen Meinung den Judenhaß, der sich mit der antisowjetischen Kriegspropaganda paarte. In diesem Klima kam es zum Pogrom von laşi und der Schreckenszeit für die Juden im Aufmarschgebiet der Heere, in der wohl 55000 Juden umkamen.

In Bessarabien wurden 1942 nurmehr etwas über 200 Juden gezählt; die anderen waren in die Sowjetunion geflohen oder dorthin deportiert bzw. nach Transnistrien abgeschoben worden. Außer den in der Bukowina verbliebenen etwa 20000 Juden gilt für die anderen Gebiete Ähnliches. Eine stichhaltige Bilanz der Zahlen für diesen gesamten Bereich kann aufgrund der momentanen Quellensituation noch nicht erstellt werden.

Die Juden in Binnenrumänien, also dem Altreich, Südsiebenbürgen, dem Banat und dem südlichen Kreischgebiet, überstanden die Schreckenszeit in Rumänien relativ am besten. Neben den diskriminierenden Sonderbestimmungen im zivilrechtlichen, arbeitsrechtlichen und fiskalischen Bereich hatten sie Schikanen auf dem Wohnsektor zu erdulden. Auch wurden Juden aus ländlichen Wohngegenden in gröBere Stādte evakuiert. Für diese, wie auch für eine gewisse Zahl aus den Ostgebieten evakuierter jüdischer Familien, mußten die ortsansässigen Kultusgemeinden finanziell aufkommen. Jüdische Jugendliche des Binnenlandes sowie aus den Reihen der Evakuierten, die im militärdienstpflichtigen Alter standen, wurden zu Arbeitsdiensten eingezogen. ${ }^{78}$

\section{Die statistischen Quellen}

Wurden bisher insbesondere die weit verstreut liegenden Archivalien herangezogen und die eher spärliche Literatur berücksichtigt, sollen im folgenden die Aussagemöglichkeiten der statistischen Quellen überprüft werden. Die Bevölkerungsstatistik Ru-

74 Brief von Marschall Antonescu an W. Filderman vom19.10.1941, NA 871.4016/287.

73 Gold, Geschichte Bukowine, Bd. 2, S. 14 und passim.

76 Ebenda, S. $13 f$.

77 Ebenda, S. 14, 19. Vgl. auch Antonescus Anklage gegen die ostrumänischen Juden, in seinem Brief an W. Filderman vom 19.10.1941, NA 871.4016/287.

78 Dazu verōffentlichte Hilberg eine Tabelle, vgl. Destruction, Bd. 2, S. 781. 
māniens ist im 20. Jahrhundert bislang nur einmal, 1930, sehr genau verfahren. Besonders für die Minderheiten werden diese Angaben als Fixpunkt und Ausgangsbasis aller weiteren Vergleiche herangezogen. Die Zählung von 1930 fragte nach drei Kriterien, um die Volkszugehörigkeit zu ermitteln: dem (subjektiven) ethnischen Bekenntnis, der Muttersprache und der Konfession. Letztere ist für die Statistik der Juden in Rumānien ausschlaggebend. Diese Komplexitāt statistischer Aussagemöglichkeiten strebte zwar auch die Zählung von 1941 an, sie wollte allerdings auch einen zeitbedingt latent vorhandenen Rassebegriff (als Vervollkommnung des "ethnischen Kriteriums") einführen. Die Nachkriegserhebung von 1948 berücksichtigte nur noch das Kriterium der Muttersprache zur Bestimmung der ethnischen Minderheiten; erst 1956 wurde auch wieder nach dem subjektiven ethnischen Bekenntnis gefragt.

Tabelle 1: Die jüdixcbe Bewölkerung Rumäniens in Zablen

Volkszäblungen von $1920-1977^{79}$

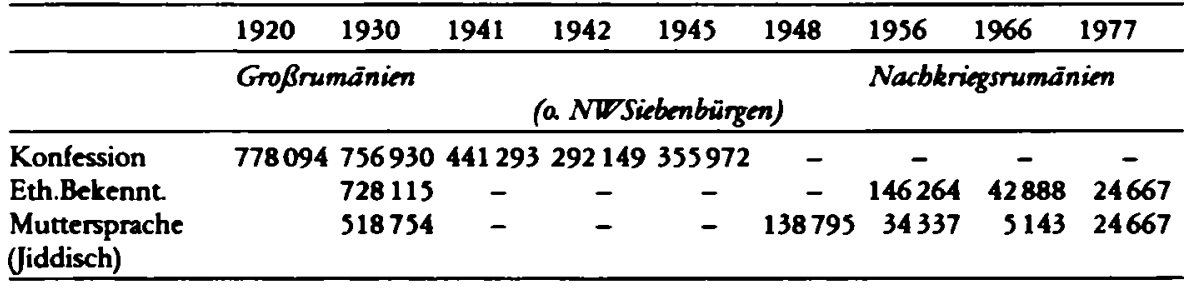

Die Anteile der einzelnen ethnischen Gruppen an der Gesamtbevōlkerung Rumāniens (a) sowie an der Stadtbevōlkerung des Landes (b) sind ebenfalls aufgrund unterschiedlicher Ausgangskriterien nicht vergleichbar. Einen Uberblick gibt die Tabelle 2.

Tabelk 2: Bewölkerungsanteile nacb Etbnie und Wobnor 60

\begin{tabular}{lrrrrrr}
\hline & \multicolumn{2}{c}{1930} & \multicolumn{2}{c}{1948} & \multicolumn{2}{c}{1956} \\
& a & b & a & b & a & b \\
\hline Rumänen & $71,9 \%$ & $58,6 \%$ & $85,7 \%$ & $80,0 \%$ & $85,7 \%$ & $79,9 \%$ \\
Magyaren & $7,7 \%$ & $11,2 \%$ & $9,4 \%$ & $12,1 \%$ & $9,1 \%$ & $12,0 \%$ \\
Juden & $4,3 \%$ & $13,6 \%$ & $0,9 \%$ & $3,5 \%$ & $0,8 \%$ & $2,5 \%$ \\
Deutsche & $4,1 \%$ & $5,3 \%$ & $2,2 \%$ & $2,4 \%$ & $2,2 \%$ & $3,5 \%$ \\
Andere & $12,0 \%$ & $11,5 \%$ & $1,8 \%$ & $2,0 \%$ & $2,2 \%$ & $2,1 \%$ \\
\hline & 100 & 100 & 100 & 100 & 100 & 100 \\
\hline
\end{tabular}

Diese Tabelle weist einen relativ hohen Anteil von Juden in den Stādten im Verhältnis zu ihrer relativ geringen Gesamtzahl in Rumānien aus. Als Stādte wurden auch die kleineren urbanen Ansiedlungen gezählt.

79 Die Zahlenangaben in den drei Tabellen wurden nach verschiedenen Quellen zusammengestellt: LNA, R 3943, 4/32388/3396, S. 21; PRO, FO 371,7700 - 91124 (Balfour Report 1922, S. 5) f. 251; Sabin Minuila (Hrsg.) Recensimîntul general al populafiei României din ... 1930, Bucureşti 1938 - 1948, Bd. 2 (1938); Recensämîntul general al populației României din 1941 ..., Bucureşti 1944; IfZ, MA 791/3 5-321719; ebenda MA 1538/1; Wilfried Krallert, Die Bevölkenungszählung in Ruminien, Wien 1943; Poulatia Republicii Populare Romāne ... 1948, in: Probleme economice 2 (1948), S. 28-45; Recensämîntul populatjiei din ... 1956. Bd. 2, Bucureşti 1960; Recensämîntul populafiei şi locuinţelor din ...1966. Bd. 1,1, Bucureşti 1969; Recensimintul populaģiei ... din 1977. Bd. 1, Bucureşti 1978.

80 Ebenda, Volkszählungen von 1930, 1948, 1956. 
Tabelle 3 zeigt die regionale Verteilung der Juden Alt-, Groß- und Nachkriegsrumāniens in den einzelnen Landesprovinzen. In allen stärker von Juden bewohnten $\mathrm{Re}$ gionen - im Norden wie im Osten des Landes - kam es zu den heftigsten Verfolgungsmaßnahmen.

Tabelle 3: Regionale Verteilung der Juden in Rumäniem Volkszählungen 1899/1956

\begin{tabular}{|c|c|c|c|c|c|c|c|c|}
\hline & \multicolumn{7}{|c|}{ Jüdische Minderheit nach der Konfession } & \multirow{2}{*}{$\begin{array}{l}\text { n. der } \\
\text { Ethnie } \\
1956\end{array}$} \\
\hline & $\begin{array}{l}1899^{1 /} \\
1900^{2}\end{array}$ & $\begin{array}{l}1910^{2} \\
1912^{1}\end{array}$ & $1920 / 22$ & 1930 & 1941 & 1942 & 1945 & \\
\hline $\begin{array}{l}\text { 1. Altrumānien } \\
=\text { Walachei } \\
\text { Moldau } \\
\text { Dobrudscha }\end{array}$ & $\begin{array}{r}266652 \\
65000 \\
195887 \\
5765\end{array}$ & $\begin{array}{c}239967 \\
- \\
- \\
-\end{array}$ & $\begin{array}{c}241088 \\
- \\
- \\
-\end{array}$ & $\begin{array}{r}264038 \\
97739 \\
162268 \\
4031\end{array}$ & $\begin{array}{c}242180 \\
- \\
- \\
-\end{array}$ & $\begin{array}{c}254871 \\
- \\
- \\
-\end{array}$ & $\begin{array}{l}\bar{z} \\
\overline{-} \\
-\end{array}$ & $\begin{array}{l}93150 \\
46971 \\
46179\end{array}$ \\
\hline $\begin{array}{l}\text { 2. Bessarabien } \\
\text { 3. Bukowina }\end{array}$ & $\begin{array}{c}228620^{3} \\
96150 \\
\end{array}$ & $\begin{array}{l}(? 266000) \\
102925^{4}\end{array}$ & $\begin{array}{r}3267000^{5} \\
128056 \\
\end{array}$ & $\begin{array}{r}206958 \\
93101 \\
\end{array}$ & $\begin{array}{l}72625 \\
71950 \\
\end{array}$ & $\begin{array}{r}227 \\
17033 \\
\end{array}$ & - & $\begin{array}{c}- \\
188589\end{array}$ \\
\hline $\begin{array}{l}\text { 4. Siebenbürgen } \\
\text { und Westrum. } \\
\text { - Siebenbūrgen } \\
\text { Banat } \\
\text { Marmarosch- u. } \\
\text { Kreischgebiet }\end{array}$ & $\begin{array}{c}159384 \\
53065 \\
- \\
-\end{array}$ & $\begin{array}{l}184154 \\
\\
64674 \\
24891 \\
94589\end{array}$ & $\begin{array}{c}181340 \\
- \\
- \\
-\end{array}$ & $\begin{array}{r}192833 \\
81503 \\
14043 \\
97287\end{array}$ & $\begin{array}{l}54538^{6} \\
- \\
- \\
-\end{array}$ & $37278^{6}$ & $\begin{array}{l}- \\
- \\
-\end{array}$ & $\begin{array}{l}43814 \\
\\
17816 \\
12990 \\
13008\end{array}$ \\
\hline Insgesamt: & 750806 & 793046 & 817484 & 756930 & $\begin{array}{c}441293 \\
(292149)^{7}\end{array}$ & $\begin{array}{c}309409 \\
(430000)^{8}\end{array}$ & 355972 & 146264 \\
\hline
\end{tabular}

Erläuterungen

1 Zählung Altrumänien

2 Zählung Osterreich-Ungarns f. Gebiete unter 3 und 4.

${ }^{3}$ Zählung Rußland (JEnzycl.)

4 auch Angabe: 95706 (Broszat)

5 auch Angabe: 238000 (JEncycl.)

6 nur Südsiebenbürgen

7 s. Hilberg

8 Angabe des WJC (s. Hilberg)

9 nur Südbukowina

Die Angaben der Erhebungen von 1930 wurden bereits bald danach von verschiedener Seite als zu gering erachtet; für die Zählung nach der Konfession sei von mindestens $\mathbf{8 0 0 0 0 0 ~ J u d e n ~ a u s z u g e h e n . ~ D i e s e ~ S c h a ̈ t z z a h l ~ g e b r a u c h t e ~ s o g a r ~ d a s ~ S t a t i s t i s c h e ~}$ Amt in seinen Antworten an den Völkerbund in Genf, und die Zahl findet sich auch in einigen Unterlagen diplomatischer Vertreter, z. B. der Briten.82 In der rechtsgerichteten Presse der Zwischenkriegszeit wurden maßlos übertriebene Zahlen - bis zu 2,5 Mill. Juden - genannt. ${ }^{83}$ Die Zählungen ab 1941 (auch die ungarische im von Rumä-

81 Quellen wie in Anm. 79 angeführt. Es gibt in der Literatur vereinzelt aus den statistischen Quellen nicht belegbare Zahlenangaben, vgl. die Eriauterungen. Diese Zahlen ließen sich nicht weiter prizisieren.

82 PRO, FO 371, 20428-106817, f. 138; ebends, 7701 - 106904, f. 78.

83 Vgl. den diese mit statistischen Daten wideriegenden Bericht von 1938 in der Petition des Jüdischen Weltbundes: LNA, R 3943, 4/32388/3396, S. $21 \mathrm{ff}$. 
nien abgetretenen Teil Siebenbürgens) stehen alle in dem Ruf, die Juden hātten sich ihnen teilweise entzogen. Inwieweit das zutrifft, ist schwer einzuschätzen. 84

Die Manipulierbarkeit der Juden betreffenden Statistiken hat in den dreißiger Jahren auf dem Felde der Innen- und der Wirtschaftspolitik mehrfach Anlaß zu Debakeln gegeben. Der verhältnismäßig hohe Anteil dieser insgesamt kleinen Minderheit an der städtischen Bevölkerung und in manchen Gebieten (vgl. Tab. 2 und 3) hat regional zu großen Spannungen geführt - besonders im Osten Rumäniens. Die Berufsstruktur der hier lebenden Juden war vergleichbar mit der in Polen und Galizien, d.h. die Juden lebten in relativ großer Armut.85 Doch in Bessarabien und der Bukowina gab es auch einen jüdischen Bauernstand, lāndlichen Grundbesitz, was wiederum die Begehrlichkeit der Rumānen schürte. ${ }^{86}$

Ausgangspunkt aller Zahlenangaben bleibt dennoch, mangels anderer Daten, die Statistik von 1930. Mögliche Fehlerquellen und die Unvermeidbarkeit von Schātzzahlen für manche Regionen und ethnischen Gruppen müssen also in Kauf genommen werden. Objektive Fehlerquellen bieten die Statistiken von 1930 bis 1956 aufgrund folgender Faktoren:

- Unterschiedliche Befragungskriterien und daraus resultierend,

- die Unvergleichbarkeit vieler statistischer Angaben per se;

- schwankende Rechtslage, besonders hinsichtlich der Staatsangehörigkeit der Juden;

- Fehlen vollständiger Einwanderungs- und Auswanderungsstatistiken;

- unverbindliche Schātzwerte bei Flüchtlingsziffern.

Schwieriger einzuschātzen sind dagegen die subjektiven Faktoren wie Unterschiede im Grad der Assimilation innerhalb der bukowinischen, altrumānischen und siebenbürgischen Judengemeinschaften, aber auch die Zählungsunwilligkeit aus Furcht vor Benachteiligung u. a. m. Am deutlichsten machen sich diese Unausgewogenheiten bei der Frage nach der Zahl der Opfer bemerkbar. Da eindeutige Quellen mit Zahlenreihen fehlen, finden sich in der gesamten Literatur zu dieser Frage weit voneinander abweichende Angaben, oft auch nur Schātzzahlen.

Wiewohl eine Ubersicht der Zahlen für die Opfer und die Davongekommenen auf den ersten Blick paradox erscheinen mag, ist im Falle Rumänien auch die Zahl der dem Holocaust entgangenen Juden völlig unbestimmt, und sie bleibt unbestimmbar. Der Hauptgrund dafür liegt in einer allzu engen Verzahnung verschiedenartiger und unterschiedlich zu gewichtender Bevölkerungsbewegungen unter den Juden Rumāniens im Zeitraum 1940 bis $1947 / 1948$. Im einzelnen handelte es sich um folgende Verschiebungen:

- die Auswanderung von Juden aus Rumānien, die während der gesamten Periode erfolgte und die mit der Auswanderung nichtrumānischer Juden über Rumāniens Territorium und Grenzen verquickt war;

84 Manuila/Filderman, Regional Development, S. 12; Oliver Lustig, Entstellungen und Verfalschungen, die das Andenken an die Opfer des Horthy-Terrors beleidigen und schädigen, S. 10 I, Bukarest, 0. J, Teil 1.

85 Darüber liegt bislang nur die Darstellung von Hans Schuster, Die Judenfrage in Rumänien, Leipzig 1939. vor, in der jedoch zahlreiche Tabellen und Berufsstatistiken enthalten sind.

86 Enc. Jud. Bd 4, Sp. 704 ff.; Gold, Geschichte Bukowine, Bd. 2, S. 4 f. 
- die Flucht von rumānischen Juden, zumindest bis Kriegsende, an der auch nichtrumänische Juden beteiligt waren;

- Deportationen von Juden aus Rumānien durch vier verschiedene Hoheitsmāchte: die Sowjets (1941 und ab Sommer 1944), die Rumänen (1941 - 1942), die Deutschen im Osten (1941/1943) und die Ungarn (1944);

- die Migration der Davongekommenen, die sich mit Wohnsitz im Gebiet Binnenrumäniens in seinen Grenzen vom Herbst 1940 befanden;

- die aus deutschen und rumānischen Arbeitslagern nach Kriegsende Zurückgekehrten. ${ }^{87}$

Alle diese Bewegungen wurden gleich nach dem 23. August 1944, dem Tag der Entmachtung Antonescus und der Einstellung des Kampfes der rumānischen Armeen gegen die Alliierten, durch eine unüberschaubare teils legalisierte, teils fluchtartige Einwanderung von Juden aus dem Gebiet östlich des Pruth und aus Ungarn nach Binnenrumānien überlagert, die in ebensowenig übersehbarer Weise zu einem beträchtlichen Teil aus Rumänien auswanderten oder flohen. Wahrscheinlich waren die meisten von ihnen der Gruppe von Juden aus Rumänien zugehörig, es waren aber auch Juden aus Polen, der Ukraine, Ungarn, der Tschechoslowakei und aus Deutschland darunter. Ihr Anteil an der jüdischen Bevölkerung Rumāniens wie an deren Auswanderung wird in den Quellen vereinzelt genannt, die Angaben sind aber oft widersprüchlich. ${ }^{88}$

Man kann die Vorgänge der Auswanderung und der Flucht von Juden aus Rumänien chronologisch gliedern in die Zeit bis 1940, die Kriegszeit bis Herbst 1944 und die frühe Nachkriegsperiode 1945 bis Ende 1947, ohne damit aber zu genaueren Angaben zu gelangen. Nochmals sei in diesem Zusammenhang betont, daß diese Bewegungen und die damit in der Sekundärliteratur verbundenen Zahlenangaben sich nicht allein auf Juden aus Rumänien beziehen. Festzuhalten bleibt auch, daß cine Trennung zwischen Flucht und Auswanderung in der gesamten Periode von 1940 bis $1947 / 1948$ nicht möglich ist.

In der dunkelsten Grauzone befinden sich, statistisch betrachtet, jene Juden aus Rumānien, denen bis zum Kriegsende die Flucht vor Deportation, Verfolgung und Terror gelungen war. Dazu sind alle zu rechnen, die während des Krieges über die deutsch-rumānische Frontlinie in die Sowjetunion geflohen, aber auch jene, die die Sowjets deportiert oder bei ihrem Abzug 1940/1941 mitgenommen hatten. Ihr weiteres Schicksal ist am wenigsten bekannt; außer dem Fluchtweg weiß man fast nichts über ihren Verbleib. Blieben sie in der Sowjetunion, kamen sie dort in Lager, gelang eine weitere Flucht und dann wohin? Die geschätzte Zahl dieser Juden aus Rumānien erscheint mit 100000 Menschen sehr hoch, ebenso die Angabe von 200000 nach der Sowjetunion verschleppter Rumānen. ${ }^{89}$

87 In dieser Frage ist nach heutigem Forschungsstand noch keine Ubersicht zu gewinnen. Verstreute Einzeldaten und -quellen dariber geben ein eher diffuses Bild, vgl. z. B. aus den Berichten der Deutschen Gesendtschaft in Bukerest in IfZ, MA 1538, dort XL 13164/2; XL 13710/A XII, b; XL 13171/A XII, c; XL 13172/E; XI 13178 B VII; XI 13178/B VIII a; vgl. auch einen amerikanischen Bericht vom Oktober 1944, NA, RG 226, 101841.

88 In einem Bericht des Verbandes der Juden Rumäniens an den Vōlkerbund vom Januar 1938 wird die Gesamtzahl dieser auslindischen Juden, um deren Weiterieitung sich u. a die chilenische und die Schweizer Gesandtschaft in Buterest bemühten, mit unter 10000 angegeben, LNA, R 3943, 4/32402/13396, S. $9 \mathrm{ff}$.

89 Mänuila/Fildermen, Regional Development, S. 5, 8; Carp, Cartea Neagrä, Bd. 1, schätzt, es seien nur einige Tausend gewesen (S. 20). 
Die Flucht anderer Gruppen von Juden aus Rumānien wāhrend und kurz nach dem Krieg, die meist von internationalen caritativen Verbänden gefördert wurde, ist besser nachzuweisen, wenn auch weder zahlenmäßig genauer noch nach Einzelheiten wie Fluchtwegen und -zielen zu belegen. Die zwei hauptsāchlichen Rettungswege bzw. -arten waren Schiffstransporte über das Schwarze Meer in die relative Sicherheit des Nahen Ostens und Grenzübergänge in andere Länder als die Sowjetunion. Sie geschahen meist mit stillschweigender Billigung der Behörden. Uber diese Fluchtvorgänge wurden bis heute rumänischerseits keine Auswanderungsstatistiken veröffentlicht; es war auch nicht festzustellen, ob darüber überhaupt Zahlen vorhanden sind. Die bislang erfolgten Bemühungen, aus den Einwanderungsstatistiken mancher Länder, besonders Palästinas, mehr Aufschluß über dieses Geschehen zu erhalten, brachten nur bescheidene Erfolge. 90

Selbst die Zahl der in Rumānien nach Kriegsende, 1945 bzw. 1948 (1. Volkszählung), verbliebenen Juden ist nicht bekannt. Anhand einer wahrscheinlich aus internen Akten der jüdischen Kultusgemeinden stammenden Quelle geben Mānuilā und Filderman, ohne die Zahl zu kommentieren, 355972 Juden im Jahre 1945 in Rumànien an. In anderen Arbeiten werden voneinander abweichende Zahlen genannt. Erwähnenswert ist die Angabe der URO, da sie Mănuilä und Fildermans Angaben überschreitet und als Quelle den World Jewish Congress nennt.91

Diese Zahlen für 1945 sowie die Angaben der ersten beiden Nachkriegszählungen von 1948 und 1956, die in Tabelle 3 ausgewiesen sind, legen die Vermutung einer dramatischen Verringerung der Gesamtzahl der Juden Rumāniens nahe. Es scheint, als sei die Zahl der Juden in diesem Land zuerst während des Zweiten Weltkriegs und dann abermals im Verlauf der ersten drei Nachkriegsjahre um jeweils die Hälfte zurückgegangen.

\section{Grenzen statistischer Betrachtungsweise}

Ausgehend vom dreifach gefācherten Ergebnis der Volkszāhlung von 1930 zeigt der rein numerische Vergleich mit den sieben darauffolgenden Erhebungen, die zwischen 1941 und 1977 stattfanden, tendenziell eindeutig eine stetige Rückläufigkeit der Zahl der Juden Rumäniens, und zwar auf etwa ein Fünftel im Jahre 1956 und schließlich 1977 auf eine statistisch bereits nicht mehr erhebliche Anzahl.92

Die Zahl der Juden Rumāniens bei Kriegsende ist nicht genau bekannt; veröffentlichte Angaben liegen zwischen 356000 und 430000.93 Auch wenn diese Zahlen eher auf Schātzungen beruhen, ist dennoch evident, daß die massive Verringerung der Zahl der Juden seit 1930 nur zu einem Teil den Kriegsgreueln und den antisemitischen Ausschreitungen zuzuschreiben ist. Die anderen für diese Rückläufigkeit wichtigen Faktoren wurden schon genannt - Flucht und Auswanderung aus Rumānien (vor, während und unmittelbar nach dem $Z$ weiten Weltkrieg), grenzverschiebungsbedingte

90 Vgl. dazu Mànuilä/Filderman, Regional Development, S. 5.

91 Vgl. Tabelie 3.

92 Vgl. Tabelle 1.

93 Vgl. Tabelle 3. Die erste Angabe ist von Mänuila/Filderman, Regional Development, S. 4; die zweite steht im URO-Gutachten vom 4.5.1982, ,Verfolgungsopfer in Rumänien" (Typoskript 4 S.) S. 4. 
Bevölkerungsrückgänge und -umschichtungen. In der Beurteilung der rücklāufigen Zahl der Juden Rumāniens rangieren diese Faktoren vor den unmittelbar dem rumänischen Holocaust zuzuschreibenden Opfern. Angesichts dieser komplexen Sachlage wie der weitgehend fehlenden wissenschaftlichen Untersuchungen zum Thema wird verstāndlich, warum in den einschlägigen Publikationen beim Stichwort Rumānien so unterschiedliche Angaben und Schātzungen enthalten sind.

Aus den wenigen bereits zugänglich gewordenen rumänischen Quellen ist nach heutigem Stand zu entnehmen, daß genauere Zahlenangaben vermieden werden: Weder die Zahl der Opfer der beiden Pogrome von 1941 oder die der im Zusammenhang des beginnenden Ostfeldzugs Ermordeten wird genannt, noch wird die der nach Transnistrien Deportierten sowie der dort 1943 noch Lebenden bzw. der 1945 in Rumänien vorgefundenen Juden erwāhnt; auch die Transnistrien betreffenden Vorgänge sind bisher nicht Thema rumānischer Arbeiten gewesen. Daher bleiben einzelne Bereiche dieser Nachforschungen weiterhin auf "Expertenangaben“ begrenzt.

Nach Uberprüfung der komplexen Fakten- und Sachlage erscheinen die von Mănuilă und Filderman bereits 1957 veröffentlichten Zahlen als die stichhaltigsten. Ein nicht unwichtiges Argument, das die URO-Publikationen betrifft, mag diese Ansicht stützen. Wāhrend diese bis Ende der siebziger Jahre überwiegend die Zahlenangaben von Matatias Carp zugrunde legten (die weit höher liegen als die von Mănuilä-Filderman), enthält ein knapp gehaltenes URO-Gutachten aus dem Jahre 1982 andere Ziffern.94 Ohne nāhere Begründung nāhert sich die URO damit der Darstellung Mänuilä-Fildermans.

Alle Zahlenreihen und Auflistungen gehen auf die Statistik des Jahres 1930 zurück. Die Volkszāhlungen von 1941 und 1942 erfahren dagegen bei den einzelnen Autoren interpretationsbedingte Unterschiede, wahrscheinlich weil die Autoren die Pressestimmen über eine erhōhte jüdische Präsenz 1940/1941 unterschiedlich bewerteten. Diese Interpretationsspielrāume werden bis heute eingeräumt. Dafür ist die Zahl der Juden in Nordwestsiebenbürgen beispielhaft: nach der ungarischen Zählung von 1941 betrāgt sie nur 151000 , nach heutigen rumānischen Angaben jedoch über 162000 , dagegen werden im URO-Gutachten von 1982 immerhin 157000 Juden genannt. 95

Während die Angaben bei Mănuilă-Filderman auf dem historisch komplexen Hintergrund von Entrechtung, Abschiebung, Flucht, Deportation, Auswanderung und Rückkehr nach Kriegsende erstellt wurden, lassen fast alle übrigen Arbeiten über den Holocaust den Eindruck entstehen, die Zahl der Opfer könne unmittelbar aus der rückläufigen Zahl der Juden in Rumānien abgeleitet werden. Bei Matatias Carp betrāgt die Zahl der Opfer rund 400000, wovon etwa 265000 Rumānien und etwa 122000 Ungarn angelastet werden. Die Deportationen der Sowjets aus Bessarabien, der Bukowina und Transnistrien $(1941,1944)$ fehlen in dieser Darstellung, und die Zahl der geflüchteten Juden wird minimalisiert. Die Encyclopaedia Judaica übernimmt die Angaben Carps.96 Das URO-Gutachten von 1982 scheint Carp stillschweigend zu korrigie-

94 URO-Gutachten, ebenda Die vierbandige URO-Dokumentation, in der auf Rumänien Bezug genommen wind, stellt bereits veröffentlichte Quellen, z. T. in deutscher Ubersetzung, zusammen.

95 URO-Gutachten, ebenda, S. 2; Carp, Cartea Neagri, Bd. 1, S. 20 (121 270 Opfer); Der hortystisch-faschistische Terror im Nordwesten Siebenbürgens (Koord.: Mihaj Fätu u. a), Bukarest 1986, S. 308

96 Enc. Jud., Bd. 14, Sp. 403; Carp, Cartea Neagrä, Bd. 1, S. 18 f. 
ren. Ausgangspunkt sind hier 765218 Juden im Jahre 1939 (nach Angaben vom World Jewish Congress) auf dem Territorium Großrumāniens. Die Zahl der Heimgekehrten ist zwar im Gutachten der URO niedriger angegeben als in der Studie Mănuilä-Fildermans aus dem Jahre 1957, doch entspricht die Zahl der Opfer mit rund 212000 den Angaben des Jahres 194797; das Gutachten übergeht jedoch die Opferzahlen aus Binnenrumānien gänzlich ( $\ldots$... im großen und ganzen keine wesentlichen Todesopfer ${ }^{\text {"98)}}$ ). In Hilbergs Untersuchung ist die Zahl der nach Transnistrien Deportierten mit 160000 viel höher angegeben als bei Mănuilä-Filderman, und damit ist auch die Angabe der jüdischen Opfer insgesamt - die einmal mit 270000, ein anderes Mal mit 370000 aufscheint - irreführend. 99

Tabelle 4 enthālt abschließend den Versuch einer Ubersicht über die Zahl der Opfer, der Vermißten und der Uberlebenden des rumānischen Holocaust, der die Angaben von Mănuilă und Filderman zugrunde legt.

Tabelle 4: Die Zabl der Opfer, Vermißlen und Uberkebenden 1940-1945

\begin{tabular}{|c|c|c|c|c|c|c|}
\hline & 1930 & 1941 & $1940 / 1941$ & $1941-1944$ & 1944 & $\begin{array}{l}\text { Opfer } \\
1945\end{array}$ \\
\hline $\begin{array}{l}\text { 1. Nord- } \\
\text { westsie- } \\
\text { benbür- } \\
\text { gen }\end{array}$ & 148295 & 151125 & & & 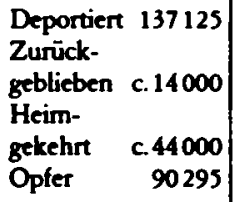 & 90295 \\
\hline $\begin{array}{l}\text { 2. Nōrdl. } \\
\text { Buko- } \\
\text { wina } \\
\text { Bessara- } \\
\text { bien } \\
\text { Herga- } \\
\text { Distrikt }\end{array}$ & 275419 & 126000 & $\begin{array}{l}\text { Deportierte/SU c. } 100000 \\
\text { Deport/Transnistrien } \\
\text { Zurückgeblieben } \\
\text { Heimgekehrt } \\
\text { Opfer/Rum. ? } \\
\text { Opfer/SU c. } 49419 \\
\text { Opfer/Trans. }\end{array}$ & $\begin{array}{l}\text { c. } 109000 \\
\text { c. } 17000 \\
\text { c. } 54500\end{array}$ & & $\begin{array}{c} \\
\\
\\
\\
\\
\\
\\
? \\
\text { c. } 49419 \\
\text { c. } 54500\end{array}$ \\
\hline $\begin{array}{l}\text { 3. Ubriges } \\
\text { Rumä- } \\
\text { nien }\end{array}$ & 333216 & c. 315293 & $\begin{array}{l}\text { Massaker, Pogrome c. } 7.000 \\
\text { Deportierte } \\
\text { Zurückgeblieben } \\
\text { Heimgekehrt } \\
\text { Opfer }\end{array}$ & $\begin{array}{l}\text { c. } 40000 \\
\text { c. } 275000 \\
\text { c. } 30000 \\
\text { c. } 10000\end{array}$ & & $\begin{array}{l}\text { c. } 7000 \\
\text { c. } 10000\end{array}$ \\
\hline & 756930 & c. 592418 & & & & c. 211214 \\
\hline
\end{tabular}

97 URO-Gutachten 1982, S. 3 f.

98 Ebenda, S. 3.

99 Hilberg, Destruction, Bd. 2, S. 771, 776; Bd. 3, S. 1120, 1048. 
